Article

\title{
Optimization of Pre-Inoculum, Fermentation Process Parameters and Precursor Supplementation Conditions to Enhance Apigenin Production by a Recombinant Streptomyces albus Strain
}

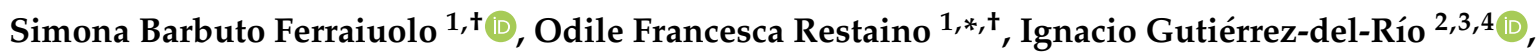 \\ Riccardo Ventriglia ${ }^{1}$, Marcella Cammarota ${ }^{1}$, Claudio J. Villar ${ }^{2,3,4}$, Felipe Lombó ${ }^{2,3,4}$ (D) and Chiara Schiraldi ${ }^{1, *}$ (D)
}

check for updates

Citation: Barbuto Ferraiuolo, S.; Restaino, O.F.; Gutiérrez-del-Río, I.; Ventriglia, R.; Cammarota, M.; Villar, C.J.; Lombó, F.; Schiraldi, C. Optimization of Pre-Inoculum, Fermentation Process Parameters and Precursor Supplementation Conditions to Enhance Apigenin Production by a Recombinant Streptomyces albus Strain. Fermentation 2021, 7, 161. https://doi.org/ $10.3390 /$ fermentation7030161

Academic Editor: Cristiano Varrone

Received: 29 July 2021

Accepted: 18 August 2021

Published: 21 August 2021

Publisher's Note: MDPI stays neutral with regard to jurisdictional claims in published maps and institutional affiliations.

Copyright: (c) 2021 by the authors. Licensee MDPI, Basel, Switzerland. This article is an open access article distributed under the terms and conditions of the Creative Commons Attribution (CC BY) license (https:/ / creativecommons.org/licenses/by/ $4.0 /)$.
1 Department of Experimental Medicine, Section of Biotechnology and Molecular Biology, University of Campania "Luigi Vanvitelli", Via De Crecchio 7, 80138 Naples, Italy; simona.barbutoferraiuolo@unicampania.it (S.B.F.); riccardo_ventriglia@hotmail.it (R.V.); marcella.cammarota@unicampania.it (M.C.)

2 Research Group BIONUC (Biotechnology of Nutraceuticals and Bioactive Compounds), Departamento de BiologíaFuncional, Área de Microbiología, Universidad de Oviedo, 33006 Oviedo, Spain; nachogutiem@gmail.com (I.G.-d.-R.); cjvg@uniovi.es (C.J.V.); lombofelipe@uniovi.es (F.L.)

3 IUOPA (Instituto Universitario de Oncología del Principado de Asturias), 33006 Oviedo, Spain

4 ISPA (Instituto de Investigación Sanitaria del Principado de Asturias), 33011 Oviedo, Spain

* Correspondence: odilefrancesca.restaino@unicampania.it (O.F.R.); chiara.schiraldi@unicampania.it (C.S.); Tel.: +39-815667666 (O.F.R.); +39-815667654 (C.S.); Fax: +39-815667546 (O.F.R. \& C.S.)

$\dagger$ These authors contributed equally to this manuscript.

Abstract: Streptomyces albus J1074-pAPI (Streptomyces albus-pAPI) is a recombinant strain constructed to biotechnologically produce apigenin, a flavonoid with interesting bioactive features that up to now has been manufactured by extraction from plants with long and not environmentally friendly procedures. So far, in literature, only a maximum apigenin concentration of $80.0 \mu \mathrm{g} \cdot \mathrm{L}^{-1}$ has been obtained in shake flasks. In this paper, three integrated fermentation strategies were exploited to enhance the apigenin production by Streptomyces albus J1074-pAPI, combining specific approaches for pre-inoculum conditions, optimization of fermentation process parameters and supplementation of precursors. Using a pre-inoculum of mycelium, the apigenin concentration increased of 1.8-fold in shake flask physiological studies. In $2 \mathrm{~L}$ batch fermentation, the aeration and stirring conditions were optimized and integrated with the new inoculum approach and the apigenin production reached $184.8 \pm 4.0 \mu \mathrm{g} \cdot \mathrm{L}^{-1}$, with a productivity of $2.6 \pm 0.1 \mu \mathrm{g} \cdot \mathrm{L}^{-1} \cdot \mathrm{h}^{-1}$. The supplementation of $1.5 \mathrm{mM}$ L-tyrosine in batch fermentations allowed to obtain an apigenin production of $343.3 \pm 3.0 \mu \mathrm{g} \cdot \mathrm{L}^{-1}$ in only $48 \mathrm{~h}$, with an increased productivity of $7.1 \pm 0.1 \mu \mathrm{g} \cdot \mathrm{L}^{-1} \cdot \mathrm{h}^{-1}$. This work demonstrates that the optimization of fermentation process conditions is a crucial requirement to increase the apigenin concentration and productivity by up to 4.3 - and 10.7 -fold.

Keywords: aeration; agitation; apigenin; batch fermentation; L-tyrosine; precursor supplementation; pre-inoculum; process optimization; Streptomyces albus J1074

\section{Introduction}

Apigenin is a widely distributed flavonoid typically found in vegetables and herbs that are generally consumed in the human daily diet, such as parsley, chamomile and oregano [1,2]. Specifically, apigenin is a flavone whose chemical structure is made of two aromatic rings linked to a third heterocyclic pyran ring, decorated with hydroxyl groups $[3,4]$. Nowadays, apigenin is one of the most renowned phenolic compounds proposed as a drug and food supplement thanks to its proven antioxidant, anti-carcinogenic and anti-inflammatory effects, as it is capable of modulating several signaling pathways through the activation or suppression of different genes, particularly those involved in cell 
cycle arrest and apoptosis $[5,6]$. These properties, in addition to low toxicity and poor adverse effects, have recently made apigenin an interesting molecule in cancer prevention or as an adjuvant in the treatment of breast, lung, liver, skin, blood, colon, prostate, pancreatic, cervical, oral and stomach tumors [6-12]. Apigenin anti-inflammatory and antioxidant properties proved useful in the prevention of inflammatory events associated with obesity, atherogenesis and osteoarthritis [13-16] and in the alleviation of the symptoms of neurodegenerative diseases, such as Alzheimer's or Parkinson's, and of depression [17,18]. Moreover, apigenin showed interesting potentialities against different microbial pathogens such as Staphylococcus aureus, Helicobacter pylori, Streptococcus mutans, Candida albicans and C. parapsilosis [19-23] and diverse viruses such as Herpes simplex, hepatitis C, influenza and more recently against SARS-CoV-2 coronavirus [24-26]. To exert a biological effect in humans, apigenin has to be consumed in a range from 20 to $50 \mathrm{mg} \cdot \mathrm{kg}_{\text {bodyweight }}{ }^{-1}$, but its content in edible plants is so low (from 106-903 $\mu \mathrm{g}_{\text {apigenin }} \cdot \mathrm{g}^{-1}$ edible portion) that its average daily intake has been estimated to be about $3 \mathrm{mg} \cdot$ day $^{-1}$ in Europe and in a range between 0.2 and $1.35 \mathrm{mg} \cdot$ day $^{-1}$ in the USA [2,5]. Thus, the development of a nutraceutical formulation containing apigenin represents the only way to increase its intake in the human daily diet. Industrial production of apigenin is time-consuming and expensive, mainly based on extraction from Matricaria chamomilla L. ligules with a water/ethanol mixture, followed by hydrolysis with hydrochloric acid and a final step of purification by crystallization using ethanol or other organic solvents [27]. This manufacturing process does not allow to recover apigenin in sufficient quantities to meet the increasing market demand, as the overall yield is about $5.2 \%$ [27]. As an alternative, a biotechnological approach to produce apigenin could lead to a significant reduction in the manufacturing costs, increase its availability on the market, and push the industry to employ more eco-friendly processes [27]. In the last few years, the elucidation of the flavonoid biosynthetic pathway of plants has contributed to pave the way for heterologous expression of these phytochemicals in different microbial hosts $[27,28]$. The biosynthetic pathways of most of the flavonoids have three steps in common that are catalyzed by phenylalanine ammonia lyase (PAL), cinnamate 4-hydroxylase $(4 \mathrm{CH})$ and 4-coumaroyl $\mathrm{CoA}$ ligase $(4 \mathrm{CL})$ and that lead to the formation of the common intermediate $p$-coumaroyl-CoA $[29,30]$. For apigenin biosynthesis, three other reactions occur, in which the chalcone synthase (CHS) combines one molecule of $p$-coumaroyl-CoA and three molecules of malonyl-CoA to generate the naringenin chalcone through a condensation reaction. Then, the chalcone isomerase $(\mathrm{CHI})$ catalyzes the closure of the heterocycle, leading to the formation of naringenin that is specifically converted in apigenin by the flavone synthase oxidoreductase (FNS) [29]. Recent studies have reported the possibility of apigenin heterologous expression and production in microorganisms such as Escherichia coli, Saccharomyces cerevisiae and Streptomyces venezuelae [31-33]. However, in all of these works, the host microorganisms were not able to produce the apigenin precursors by themselves and the biosynthesis could be only achieved by addition in the growth medium of L-tyrosine (L-Tyr), p-coumaric acid or naringenin [33-37]. In a recent paper, instead, a rearrangement of the flavonoid biosynthetic pathway was achieved with the direct conversion of L-tyrosine to $p$-coumaric acid by a tyrosine ammonia lyase (TAL) [30] (Figure 1).

The gene coding for TAL enzyme, together with the genes coding for $4 \mathrm{CL}, \mathrm{CHS}$, $\mathrm{CHI}$ and FNS enzymes, were cloned in a plasmid, called pAPI; a strategy never reported before in Streptomyces [30]. Cultivations of the new strain Streptomyces albus J1074-pAPI (Streptomyces albus-pAPI), performed only in $250 \mathrm{~mL}$ - baffled shake flasks with $25 \mathrm{~mL}$ of R5A medium after inoculation with spores, led to a maximum apigenin concentration of $80 \mu \mathrm{g} \cdot \mathrm{L}^{-1}$ in $120 \mathrm{~h}$, with a process productivity of $0.6 \mu \mathrm{g} \cdot \mathrm{L}^{-1} \cdot \mathrm{h}^{-1}$ [30]. In the same paper, the authors demonstrated that, by using a pre-inoculum of conditioned spores, grown for ten days, an increase in the kinetics of production was obtained, but not in the apigenin titer, with a maximum at $72 \mathrm{~h}$ and an enhanced productivity of $1.1 \mu \mathrm{g} \cdot \mathrm{L}^{-1} \cdot \mathrm{h}^{-1}$. However, the possibility to produce apigenin directly starting from a mycelium inoculum, thus reducing the process time for spore conditioning, was not investigated. In addition, a medium 
supplementation strategy with $13.5 \mathrm{mM}$ sodium malonate and $1.5 \mathrm{mM}$-coumaric acid, as apigenin precursors, alone or in combination, was also tested, but was not successful in increasing the production nor the productivity. Thus, the optimization of the fermentation conditions of Streptomyces albus-pAPI for the enhancement of apigenin production and the scale-up of the biotechnological process in a bioreactor with controlled parameters still remain unexplored. As it is known, the Streptomyces genus is characterized by a complex life cycle in which the morphological and development stages greatly influence the biosynthesis of metabolites [38]. In the design of a biotechnological production process of industrially interesting molecules, the optimization of the fermentation conditions such as temperature, $\mathrm{pH}$, medium composition, oxygen concentration, aeration and stirring is strictly necessary to increase the production and productivity yields of the desired product $[39,40]$. In this paper, for the first time, an integrated optimization of the critical fermentation process parameters was conducted to enhance the apigenin production by the recombinant $S$. albus-pAPI strain. Preliminary shake flask studies were used to replace the use of the spore pre-inoculum directly with a mycelium seed, avoiding any conditioning step. Successively, stirring and aeration profiles were set up to obtain an optimized dissolved oxygen concentration in the fermentation vessel (2 L working volume) and to increase the apigenin productivity. Supplementation of the growth medium with appropriate apigenin precursors, such as L-tyrosine and biotin, was also investigated in order to overcome eventually occurring bottlenecks in the apigenin biosynthesis.

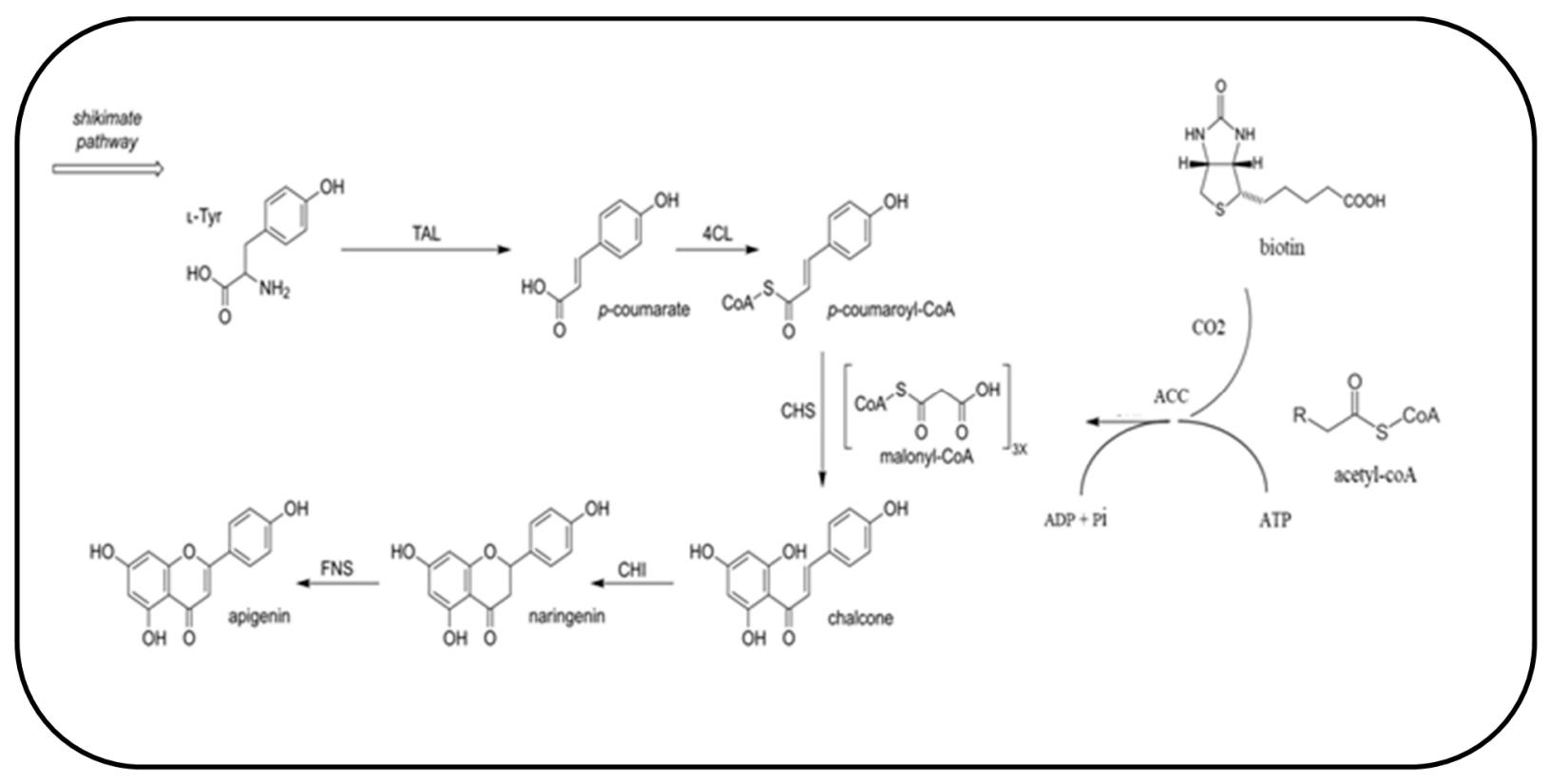

Figure 1. Biosynthetic pathway of apigenin in Streptomyces albus-pAPI.

\section{Materials and Methods}

\subsection{Materials}

The agar used for the medium plates, the casein acid hydrolysate and the meat peptone used in the R5A medium or in Bennet medium were from Oxoid (Thermo Fisher, Waltham, MA, USA), while the yeast extract was from Difco (Thermo Fischer, Waltham, MA, USA). All the other media components, salts and trace elements, the antibiotic, the sodium hydroxide, the sulfuric acid, the antifoam 104, the DMSO and the apigenin standard were furnished by Sigma-Aldrich (USA). L-tyrosine and biotin supplemented to the growth medium in some experiments were also from Sigma-Aldrich (USA). The trypticasein soy broth (TSB) was from Laboratorios Conda S.A. (Spain). All the chemicals and the organic solvents used for the apigenin extraction and the UHPLC analyses were from Carlo Erba (Italy). The $\mathrm{NaOH}$ solution used to prepare the buffer in high-performance anion exchange 
chromatography with pulsed amperometric detection (HPAE-PAD) analyses was from J.T. Baker (The Netherlands).

\subsection{Microorganism and Media}

The microorganism Streptomyces albus J1074-pAPI was constructed by insertion in the wild type strain of a plasmid, named pAPI, containing five synthetic genes forming the apigenin plant biosynthetic pathway and a selectable marker represented by a gene inducing thiostrepton resistance, as previously reported [30]. The strain was propagated as spore colonies on Bennet agar medium plates $\left(20.0 \mathrm{~g} \cdot \mathrm{L}^{-1}\right.$ agar, $10.0 \mathrm{~g} \cdot \mathrm{L}^{-1}$ glucose, $1.0 \mathrm{~g} \cdot \mathrm{L}^{-1}$ meat peptone, $2.0 \mathrm{~g} \cdot \mathrm{L}^{-1}$ casein acid hydrolysate, and $1.0 \mathrm{~g} \cdot \mathrm{L}^{-1}$ yeast extract) that were then stored at $4{ }^{\circ} \mathrm{C}$. To obtain the stocks (or research working cell banks) of spores, single colonies from the Bennet agar medium plates were used to seed several TSB agar medium plates $\left(20.0 \mathrm{~g} \cdot \mathrm{L}^{-1}\right.$ agar, $2.5 \mathrm{~g} \cdot \mathrm{L}^{-1}$ glucose, $17.0 \mathrm{~g} \cdot \mathrm{L}^{-1}$ pancreatic digest of casein, $3.0 \mathrm{~g} \cdot \mathrm{L}^{-1}$ papaic digest of soybean, $5.0 \mathrm{~g} \cdot \mathrm{L}^{-1} \mathrm{NaCl}$ and $2.5 \mathrm{~g} \cdot \mathrm{L}^{-1} \mathrm{~K}_{2} \mathrm{HPO}_{4}$ ) that were then incubated at $30{ }^{\circ} \mathrm{C}$ for $168 \mathrm{~h}$ in a rotary air shaker (Infors HT Incubator, Bottmingen, Switzerland). Each plate was then re-suspended in a $20 \%(v / v)$ glycerol stock solution and the obtained stocks were then stored at $-80{ }^{\circ} \mathrm{C}$. The mycelium stocks (or research working cell bank) were instead obtained by re-suspending single colonies from the Bennet agar medium plates in two $250 \mathrm{~mL}$ shake flasks containing $25.0 \mathrm{~mL}$ of TSB medium. The shake flasks were incubated at $30^{\circ} \mathrm{C}$ and $250 \mathrm{rpm}$ for $72 \mathrm{~h}$ in the rotary air shaker (Infors HT Incubator, Bottmingen, Switzerland). At the end of the run, the shake flasks were centrifuged at $4000 \mathrm{rpm}$ and at $4{ }^{\circ} \mathrm{C}$ for $10 \mathrm{~min}$ (Avanti J-20XP, Beckman Coulter, Brea, CA, USA). After centrifugation, the biomass was re-suspended in a $20 \%(v / v)$ glycerol stock solution and the obtained stocks (or research working cell bank) were then stored at $-80{ }^{\circ} \mathrm{C}$. The TSB medium was also used for the inoculum of the bioreactor experiments. The strain was grown in both shake flask and in bioreactor experiments on a semi-defined medium (R5A medium containing $103.0 \mathrm{~g} \cdot \mathrm{L}^{-1}$ sucrose, $10.0 \mathrm{~g} \cdot \mathrm{L}^{-1}$ glucose, $0.1 \mathrm{~g} \cdot \mathrm{L}^{-1}$ casein acid hydrolysate, $5.0 \mathrm{~g} \cdot \mathrm{L}^{-1}$ yeast extract, $1.12 \mathrm{~g} \cdot \mathrm{L}^{-1} \mathrm{MgCl}_{2}, 0.25 \mathrm{~g} \cdot \mathrm{L}^{-1} \mathrm{~K}_{2} \mathrm{SO}_{4}$, $21.0 \mathrm{~g} \cdot \mathrm{L}^{-1} \mathrm{MOPS}$ and $2 \mathrm{~mL} \cdot \mathrm{L}^{-1}$ of a trace element solution made of $40 \mathrm{mg} \cdot \mathrm{L}^{-1} \mathrm{ZnCl}_{2}$, $200 \mathrm{mg} \cdot \mathrm{L}^{-1} \mathrm{FeCl}_{3} \cdot 6 \mathrm{H}_{2} \mathrm{O}, 200 \mathrm{mg} \cdot \mathrm{L}^{-1} \mathrm{CuCl}_{2} \cdot 2 \mathrm{H}_{2} \mathrm{O}, 10 \mathrm{mg} \cdot \mathrm{L}^{-1} \mathrm{MnCl}_{2} \cdot 4 \mathrm{H}_{2} \mathrm{O}, 10 \mathrm{mg} \cdot \mathrm{L}^{-1}$ $\mathrm{Na}_{2} \mathrm{~B}_{4} \mathrm{O}_{7} \cdot 10 \mathrm{H}_{2} \mathrm{O}$, and $\left.10 \mathrm{mg} \cdot \mathrm{L}^{-1}\left(\mathrm{NH}_{4}\right)_{6} \mathrm{Mo}_{7} \mathrm{O}_{24} \cdot 4 \mathrm{H}_{2} \mathrm{O}\right)[30,41]$. Few specific experiments in shake flasks or in batch were run supplementing the above-mentioned medium with L-tyrosine and/or biotin as precursors of the specific apigenin biosynthetic pathway. In all the experiments, the medium was sterilized in autoclave or in situ at $120^{\circ} \mathrm{C}$ for $20 \mathrm{~min}$ and the antibiotic thiostrepton $\left(5 \mu \mathrm{g} \cdot \mathrm{mL}^{-1}\right.$ in DMSO) was added after sterilization to both solid and liquid media to maintain the strain selection.

\subsection{Shake Flask Experiments}

First, shake flask experiments were performed in order to study the kinetics of the microbial growth and the apigenin production starting from an inoculum of spores or mycelium. Different runs were performed in $500 \mathrm{~mL}$ baffled shake flasks containing $50 \mathrm{~mL}$ of R5A medium, inoculated with $200 \mu \mathrm{L}$ of spore stock solutions or $1.0 \mathrm{~mL}$ of mycelium stock solutions, at $30{ }^{\circ} \mathrm{C}$ and $250 \mathrm{rpm}$ in a rotary air shaker (Infors HT Incubator, Bottmingen, Switzerland) and stopped at diverse time points up to $120 \mathrm{~h}$. Other experiments were instead performed in shake flasks to understand the influence of precursor addition on the apigenin production. In this case, the medium was inoculated with mycelium stocks after being supplemented with three different concentrations of L-tyrosine or biotin (from 0.375 to $1.5 \mathrm{mM}$ ) or contemporary with L-tyrosine and biotin in a concentration ratio of 1 to 3 . According to the experiments, the shake flasks were stopped at different time points in order to evaluate the cell dry weight, the carbon source consumption and the apigenin concentration. The cell dry weight was determined by filtering small volumes of broth cultures $(5 \mathrm{~mL})$ on $0.22 \mu \mathrm{m}$ polypropylene membranes (Millipore, Molsheim, France) that were then washed with a volume of physiological saline solution and placed in an oven (Binder, Germany) at $80^{\circ} \mathrm{C}$ for $18 \mathrm{~h}$ to achieve a constant dry weight, as previously 
reported $[42,43]$. To determine the carbon source consumption and the apigenin production, instead, the broth culture samples were centrifuged at $4{ }^{\circ} \mathrm{C}$ and $6500 \mathrm{rpm}$ for $20 \mathrm{~min}$ (Avanti J-20XP, Beckman Coulter, Brea, California, USA) and the supernatants were collected. All the shake flask experiments were run in quadruplicate.

\subsection{Batch Experiments}

Batch experiments were performed in a $2.5 \mathrm{~L}$ fermenter (Biostat CT plus, Sartorius group, Germany) with a working volume of $2.0 \mathrm{~L}$, sterilizable in situ and equipped with $\mathrm{pH}$, temperature and $\mathrm{pO}_{2}$ probes and peristaltic pumps for the addition of alkali and of acid, of antifoam and of the antibiotic. The calibration of the $\mathrm{pO}_{2}$ electrode (Mettler Toledo, Switzerland) was carried out by using a pure oxygen flow as the $100 \%$ value. The batch inoculum was prepared, seeding one or two mycelium stocks in one or two 1L baffled shake flasks containing $100 \mathrm{~mL}$ of TSB medium and $5 \mu \mathrm{g} \cdot \mathrm{mL}^{-1}$ of thiostrepton and incubating them at $30^{\circ} \mathrm{C}$ and at $250 \mathrm{rpm}$ for $72 \mathrm{~h}$ in a rotary air shaker (Infors HT Incubator, Bottmingen, Switzerland). Batch experiments were run in duplicates for $120 \mathrm{~h}$ at $30^{\circ} \mathrm{C}$ using $1.7 \mathrm{~L}$ of R5A medium containing $200 \mu \mathrm{L} \cdot \mathrm{L}^{-1}$ of antifoam and $5 \mu \mathrm{g} \cdot \mathrm{mL}^{-1}$ of thiostrepton. During the fermentations, the $\mathrm{pH}$ value was kept constant at 6.85 by addition of $5.0 \mathrm{M} \mathrm{NaOH}$ and/or $4.0 \mathrm{M} \mathrm{H}_{2} \mathrm{SO}_{4}$ solutions. Two different oxygenation conditions were maintained by modulating stirring and airflow values (in the range from 300 to $800 \mathrm{rpm}$ and between 1.0 and $2.0 \mathrm{vvm}$, respectively) in order to maintain the $\mathrm{pO}_{2}$ at the set point values of $40 \%$ or $30 \%$. During fermentation, samples of the broth $(35 \mathrm{~mL})$ were withdrawn every $24 \mathrm{~h}: 5 \mathrm{~mL}$ of broth was used to determine the cell dry weight, according to the protocol described above, while the rest of the volume was centrifuged to separate the supernatant from the biomass and to evaluate the carbon source consumption and the apigenin production. During the experiments, the process parameters were remotely controlled and collected by a digital control unit (DCU) equipped with a MFCS-win software (Braun Biotech International, Sartorius Group, Göttingen, Germany).

\subsection{Analytical Methods}

\subsubsection{Carbon Source Determination by HPAE-PAD}

Small volumes $(0.5 \mathrm{~mL})$ of the broth sample supernatants of the shake flask and batch experiments were ultra-filtered on $3 \mathrm{kDa}$ centrifugal filter devices (Millipore, Molsheim, France) at $4{ }^{\circ} \mathrm{C}$ and 12,000 rpm (Z216 MK, HermleLabortechnik GmbH, Wehingen, Germany). The permeate volumes were analyzed by high performance anion exchange chromatography with pulsed amperometric detection (ICS-3000, Thermofisher, Waltham, MA, USA) to determine the concentrations of sucrose and glucose in the medium at the different time points of the microbial growth. Runs were performed at $25^{\circ} \mathrm{C}$ by using a Carbopac PA1 column (Thermofisher, USA) and a $237 \mathrm{mM} \mathrm{NaOH}$ buffer according to a method previously reported [44,45].

\subsubsection{Apigenin Extraction and Determination by UHPLC}

Apigenin was extracted from the supernatants of shake flasks and batch experiment samples $(30 \mathrm{~mL})$ by the addition of ethyl acetate $(17 \mathrm{~mL})$ and by mixing for $30 \mathrm{~min}$ at $300 \mathrm{rpm}$ at room temperature on a shaker (Polymax 1040, Heidolph, Schwabach, Germany). After that, the samples were centrifuged at $4500 \mathrm{rpm}$ at $4{ }^{\circ} \mathrm{C}$ for $20 \mathrm{~min}$ (Avanti J-20XP, Beckman Coulter, Brea, California, USA) and the organic phases were recovered and completely evaporated by using a rotavapor (EZ-2 Personal Solvent Evaporator, Genevac, Ipswich, Suffolk, UK). After the evaporation step, samples were dissolved in $400 \mu \mathrm{L}$ of a methanol:DMSO solution (1:1 v/v) and analyzed by UHPLC (Ultimate 3000, Thermo Fischer Scientific, USA) by using a C-18 column (Nucleosil 100-5, 4x 125 mm, $5 \mu \mathrm{m}, 100 \AA$, Macherey-Nagel, Loughborough, UK) at $25^{\circ} \mathrm{C}$ and at a flow rate of $1 \mathrm{~mL} \cdot \mathrm{min}^{-1}$, in a $50 \mathrm{~min}$ run by using a gradient profile of $0.1 \%(v / v)$ TFA in milli-Q water (A) and $0.1 \%(v / v)$ TFA in acetonitrile (B) $(95.0 \%$ of $\mathrm{A}$ from 0 to $5 \mathrm{~min}$, from $95.0 \%$ to $5.0 \%$ of $\mathrm{A}$ from 5 to $40 \mathrm{~min}$, from $5.0 \%$ to $95.0 \%$ from 40 to $50 \mathrm{~min}$ ), after injecting $10 \mu \mathrm{L}$ of the sample and by detecting 
at $280 \mathrm{~nm}$. The concentration of apigenin was determined on the basis of a calibration curve obtained by injecting the apigenin standard material, dissolved in the methanol:DMSO solution $(1: 1 \mathrm{v} / \mathrm{v})$, at concentrations ranging from 0.00625 to $0.2 \mathrm{~g} \cdot \mathrm{L}^{-1}$. In both the shake flask and batch experiments, on the basis of the determined apigenin concentration, its yield coefficient on biomass $\left(\mathrm{Y}_{\mathrm{apig} / \mathrm{X}}\right)$ and its yield coefficient on substrate as the consumed carbon source $\left(\mathrm{Y}_{\mathrm{apig} / \mathrm{S}}\right)$ was calculated according to the following formulas:

$$
\mathrm{Y}_{\mathrm{apig} / \mathrm{X}}=\left[\left(\mathrm{C}_{\mathrm{apig}}\left(\mathrm{t}_{\text {final }}\right)-\mathrm{C}_{\text {apig }}\left(\mathrm{t}_{0 h}\right)\right) /\left(\mathrm{X}\left(\mathrm{t}_{\text {final }}\right)-\mathrm{X}\left(\mathrm{t}_{0 \mathrm{~h}}\right)\right)\right]
$$

and

$$
\mathrm{Y}_{\mathrm{apig} / \mathrm{S}}=\left[\left(\mathrm{C}_{\mathrm{apig}}\left(\mathrm{t}_{\text {final }}\right)-\mathrm{C}_{\mathrm{apig}}\left(\mathrm{t}_{0 \mathrm{~h}}\right)\right) /\left(\mathrm{S}\left(\mathrm{t}_{\text {final }}\right)-\mathrm{S}\left(\mathrm{t}_{0 \mathrm{~h}}\right)\right)\right],
$$

where $C_{\text {apig }}\left(t_{0 h}\right)$ is the apigenin concentration in $\mu \mathrm{g} \cdot \mathrm{L}^{-1}$ at the time zero of the experiment, $C_{\text {apig }}\left(t_{\text {final }}\right)$ is the apigenin concentration in $\mu \mathrm{g} \cdot \mathrm{L}^{-1}$ at the final point of the experiment, $X$ $\left(t_{0 h}\right)$ is the biomass concentration in $g_{\mathrm{cdw}} \cdot \mathrm{L}^{-1}$ at the time zero of the experiment, $X\left(t_{\text {final }}\right)$ is the biomass concentration in $g_{c d w} \cdot L^{-1}$ at the final point of the experiment, $S\left(t_{\text {final }}\right)$ is the residual total carbon source concentration in $\mathrm{g} \cdot \mathrm{L}^{-1}$ at the final point of the experiment and $S(\mathrm{t} O \mathrm{~h})$ is the initial total carbon source concentration in $\mathrm{g} \cdot \mathrm{L}^{-1}$ at the time zero of the experiment. In the case of bioreactor experiments, the process productivity $\left(\mathrm{W}_{\mathrm{p}}\right)$ was also calculated according to the formula $W p=\left[\left(C_{\text {apig }}\left(t_{\text {final }}\right)-C_{\text {apig }}(t 0 h)\right) /\left(t_{\text {final }}-t_{0 h}\right)\right]$, where $t_{0 h}$ is the time zero of the experiment and $t_{\text {final }}$ is the final point of the experiment.

\subsubsection{L-tyrosine Determination by UHPLC}

The same UHPLC system (Ultimate 3000, Thermo Fischer Scientific, USA) and the C18 column (Nucleosil 100-5, 4x 125 mm, 5 mm, $100 \AA$, Macherey-Nagel, Loughborough, UK) were used to analyse the concentration of L-tyrosine by slightly modifying a previously reported method by using a gradient profile of $0.1 \%(v / v)$ TFA in milli-Q water $(\mathrm{A})$ and $0.1 \%$ $(v / v)$ TFA in acetonitrile (B) with a detection at $210 \mathrm{~nm}$ [46]. L-tyrosine was determined at the different time points of the Batch $\mathrm{D}$, after ultra-filtration of the supernatants of the broth samples on $3 \mathrm{kDa}$ centrifugal filter devices (Millipore, Molsheim, France) at $4{ }^{\circ} \mathrm{C}$ and 12,000 rpm (Z216 MK, HermleLabortechnik GmbH, Wehingen, Germany). The L-tyrosine standard was prepared as a $25 \mathrm{mM}$ concentrated solution in $1 \mathrm{M} \mathrm{HCl}$ and then diluted in water in the range from 0.05 to $2.5 \mathrm{mM}$ to build a calibration curve.

\subsection{Scanning Electron Microscope Analyses}

Biomass samples of different time points of the batch experiments were analyzed using scanning electron microscopy (SEM). Broth samples $(1 \mathrm{~mL})$ were centrifuged at $4{ }^{\circ} \mathrm{C}$ and 12,000 rpm (Z216 MK, HermleLabortechnik GmbH, Wehingen, Germany), the supernatants were removed and the biomasses first washed in PBS, then fixed in a $4.0 \%$ paraformaldehyde solution in PBS in paraformaldehyde (Sigma Aldrich, Milan, Italy) (4\% in PBS). Then, they were dehydrated for $5 \mathrm{~min}$ with increasing ethanol percentage solutions (from $30.0 \%$ to $100.0 \%$ ethanol in water) and treated in a critical point dryer (EMITECH K850), sputter coated with platinum-palladium at $77 \mathrm{mAmps}$ for $120 \mathrm{~s}$ (Denton Vacuum DESKV) and observed with a field-emission scanning electron microscope (Supra 40, Zeiss, Germany, EHT $=5.00 \mathrm{kV}, \mathrm{WD}=22 \mathrm{~mm}$, detector in lens), as previously described [38,47].

\subsection{Data and Statistical Analyses}

All the data reported in this paper are average values of independent experiments calculated with their standard deviations by using a Microsoft Office Excel 2007 program (Microsoft, Redmond, Washington, USA). Statistical analyses involving comparison between groups of data, as in the case of results of different shake flask runs, were performed also with the $t$-student test by the Microsoft Office Excel 2007 program, and the data were considered significantly different if $\mathrm{p}$ values were lower than 0.05 or 0.01 . 


\section{Results}

\subsection{Shake Flask Experiments}

Initial physiological studies were performed in shake flasks in order to investigate whether seeding the cultures directly with a mycelium pre-inoculum instead of spores would influence the apigenin production ability of Streptomyces albus-pAPI. This strategy could also reduce the overall process time when compared with a conditioned spore pre-inoculum strategy (Figure 2A,B).
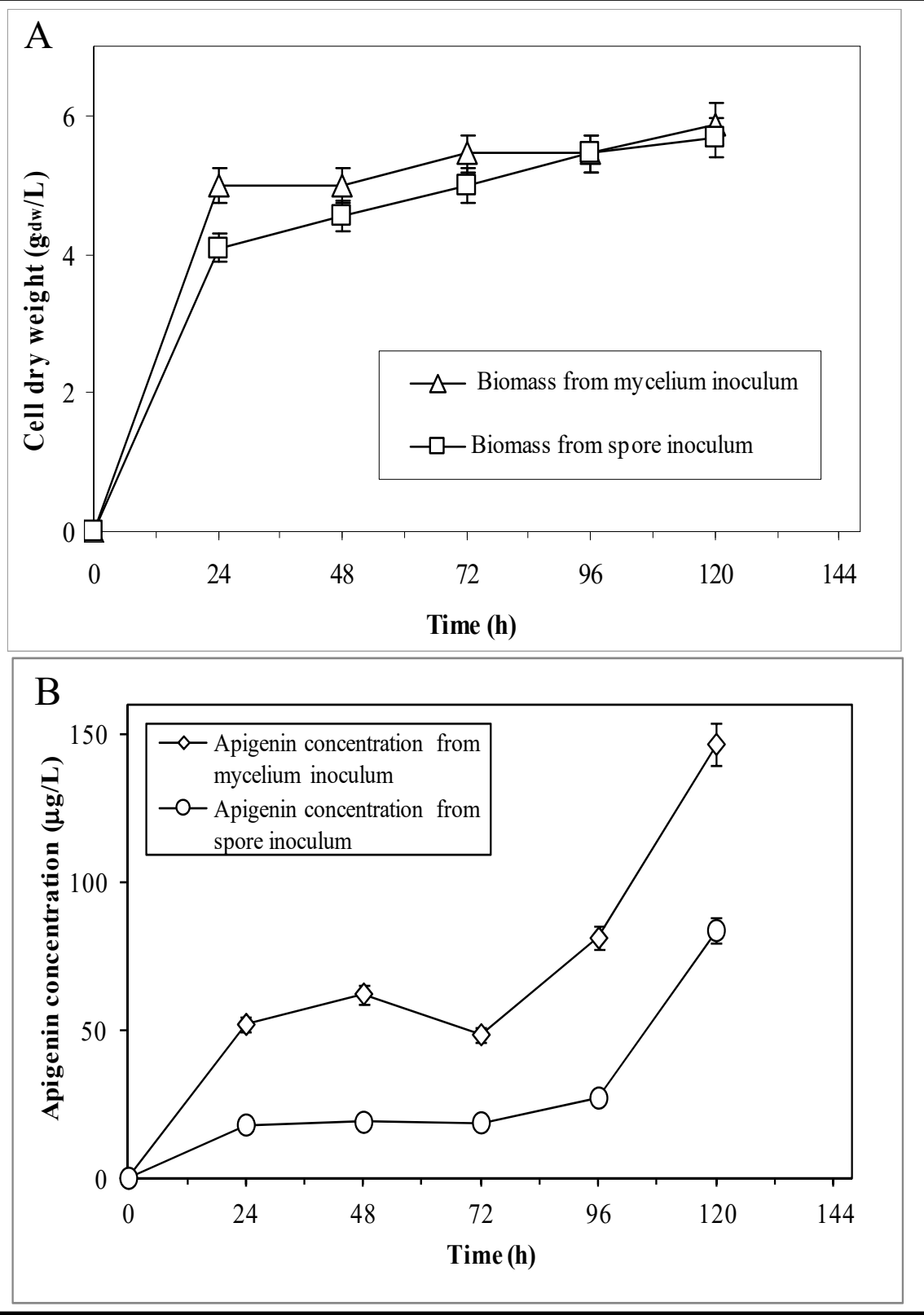

Figure 2. Kinetics of growth of Streptomyces albus-pAPI (A) and apigenin concentration (B) in shake flasks starting from spore or mycelium inoculum.

Both type of cultures, inoculated with spores or mycelium, reached a maximum rate of growth at $120 \mathrm{~h}\left(5.9 \pm 0.4 \mathrm{~g}_{\mathrm{cdw}} \cdot \mathrm{L}^{-1}\right.$ with spore and $5.7 \pm 0.4 \mathrm{~g}_{\mathrm{cdw}} \cdot \mathrm{L}^{-1}$ with mycelium), but the spore growths showed slower kinetics, with values of biomass cell dry weight lower than the mycelium growths in the range of $10.0-22.0 \%$ between 24 and $72 \mathrm{~h}$ (Figure 2A). Differences were also noted in the kinetics of apigenin production, which were quicker in the case of the mycelium pre-inoculum experiments, with values almost three times higher 
than those obtained with the spore pre-inoculum. The maximum apigenin concentration was obtained in both conditions at $120 \mathrm{~h}$ with values of $83.7 \pm 2.2$ and $146.6 \pm 10.9 \mu \mathrm{g} \cdot \mathrm{L}^{-1}$ for the spore and mycelium pre-inoculum, respectively. The correspondent productivity was $0.69 \pm 0.03$ and $1.22 \pm 0.05 \mu \mathrm{g} \cdot \mathrm{L}^{-1} \cdot \mathrm{h}^{-1}$, respectively, and the yield of apigenin on the biomass was $14.7 \pm 0.4 \mu \mathrm{g} \cdot \mathrm{g}_{\mathrm{cdw}}{ }^{-1}$ and $24.8 \pm 0.6 \mu \mathrm{g} \cdot \mathrm{g}_{\mathrm{cdw}}{ }^{-1}$, respectively (Figure $2 \mathrm{~B}$ ). No further increases in biomass and apigenin concentration were found prolonging the experiments beyond $120 \mathrm{~h}$. As the strategy of inoculating with a mycelium pre-culture allowed to increase the apigenin concentration by 1.75 -fold as well as the productivity and the yield, compared with the spore runs, this pre-inoculum approach was selected for the following shake flask and bioreactor experiments.

\subsection{Bioreactor Experiments}

Different batch experiments were run on the bioreactor for up to $120 \mathrm{~h}$ to understand the influence of the diverse dissolved oxygen percentage values, of the modulation of the stirring and the airflow conditions, and of the initial amount of pre-inoculum on the strain growth and on the apigenin production. Initially, two different stirring and aeration profiles were explored (Table 1, Figure S1).

Table 1. Bioreactor experiment parameters: stirring and aeration, $\mathrm{pO}_{2}$ set point, starting inoculum percentage and L-tyrosine supplementation.

\begin{tabular}{ccccc}
\hline Operating Process Parameters & Batch A & Batch B & Batch C & Batch D \\
\hline Stirring $(\mathrm{rpm})$ & $300-800$ & $300-600$ & $300-600$ & $300-600$ \\
Aeration $\left(\mathrm{L} \cdot \mathrm{h}^{-1}\right)$ & $78-162$ & $102-120$ & $102-120$ & $102-120$ \\
$\mathrm{pO}_{2}$ Set Point $(\% \mathrm{DO})$ & 40 & 30 & 30 & 30 \\
Starting Inoculum $(\%$ v $v)$ & 5 & - & 10 & 10 \\
L-tyrosine Supplementation & - & - & $1.5 \mathrm{mM}$ \\
\hline
\end{tabular}

In the first experiments (Batch A), the stirring (300-800 rpm) and the airflow $\left(78-162 \mathrm{~L} \cdot \mathrm{h}^{-1}\right)$ parameters were set up in order to keep the $\mathrm{pO}_{2} \geq 40 \%$ inside the bioreactor during the whole growth (Table 1, Figure 3A, Figure S1).

In these conditions, the biomass reached its highest value of $10.0 \pm 0.3 \mathrm{~g}_{\mathrm{cdw}} \cdot \mathrm{L}^{-1}$ in the first $48 \mathrm{~h}$, thus demonstrating that the growth in the more controlled batch conditions could be quicker than in mycelium shake flask experiments, producing a 1.7-fold higher maximum biomass. Additionally, the maximum apigenin concentration was reached earlier $(96 \mathrm{~h})$ with a concentration of $168.9 \pm 6.8 \mu \mathrm{g} \cdot \mathrm{L}^{-1}$ and a productivity of $1.8 \pm 0.1 \mu \mathrm{g} \cdot \mathrm{L}^{-1} \cdot \mathrm{h}^{-1}$, which was thus 1.5 -fold higher than in shake flasks with the same kind of pre-inoculum. The apigenin yield on biomass was of $17.3 \pm 0.1 \mu \mathrm{g} \cdot \mathrm{g}_{\mathrm{cdw}}{ }^{-1}$ (Table 2, Figure 3A).

Table 2. Batch experiment results.

\begin{tabular}{ccccc}
\hline & Batch A & Batch B & Batch C & Batch D \\
\hline Maximum biomass $\left(\mathrm{g}_{\mathrm{cdw}} \cdot \mathrm{L}^{-1}\right)$ & $10.0 \pm 0.3$ & $10.4 \pm 0.4$ & $11.1 \pm 0.2$ & $10.0 \pm 0.1$ \\
Maximum apigenin concentration $\left(\mu \mathrm{g} \cdot \mathrm{L}^{-1}\right)$ & $168.9 \pm 6.8$ & $160.4 \pm 5.2$ & $184.8 \pm 4.0$ & $343.3 \pm 3.0$ \\
Maximum productivity $\left(\mu \mathrm{g} \cdot \mathrm{L}^{-1} \cdot \mathrm{h}^{-1}\right)$ & $1.8 \pm 0.1$ & $3.3 \pm 0.1$ & $2.6 \pm 0.1$ & $7.1 \pm 0.1$ \\
$\mathrm{Y}_{\mathrm{apig} / \mathrm{X}}\left(\mu \mathrm{g} \cdot \mathrm{g}^{-1} \mathrm{cdw}\right)$ & $17.3 \pm 0.1$ & $15.4 \pm 0.1$ & $16.7 \pm 0.1$ & $34.3 \pm 0.1$ \\
$\mathrm{Y}_{\mathrm{apig} / \mathrm{S}}\left(\mu \mathrm{g} \cdot \mathrm{g}_{\text {totalc }}\right)$ & $3.8 \pm 0.1$ & $4.6 \pm 0.1$ & $3.2 \pm 0.1$ & $5.9 \pm 0.1$ \\
\hline
\end{tabular}




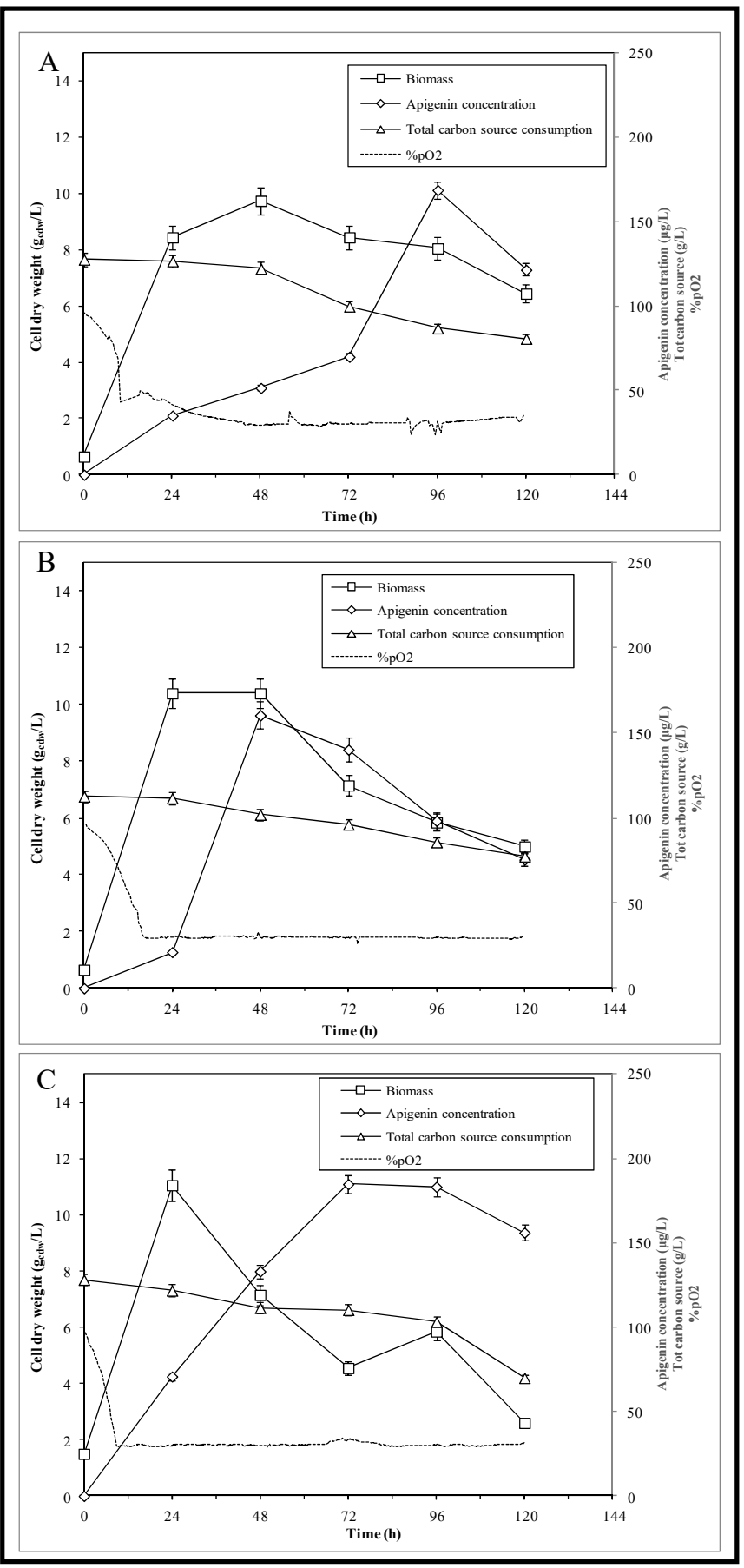

Figure 3. Bioreactor experiments of Streptomyces albus-pAPI performed by using two different stirring and aeration profiles-(A) 300-800 rpm; 78-162 L $\cdot \mathrm{h}^{-1}$ and (B) 300-600 rpm; 102-120 L $\cdot \mathrm{h}^{-1}$ —and a double percentage of initial inoculum $(\mathrm{C})(10 \% \mathrm{v} / \mathrm{v})$ : kinetics of growth and apigenin concentration, total carbon source consumption and $\% \mathrm{pO}_{2}$ profile.

The total carbon source consumption at the end of the experiments was about $46.9 \mathrm{~g} \cdot \mathrm{L}^{-1}$, with an average consumption rate of $0.4 \mathrm{~g} \cdot \mathrm{L}^{-1} \cdot \mathrm{h}^{-1}$, and thus the yield of apigenin on the total carbon source was $3.8 \pm 0.1 \mu \mathrm{g} \cdot \mathrm{g}_{\text {totalc }}{ }^{-1}$ (Table 2, Figure 3A). The $\mathrm{pO}_{2}(\%)$ profile showed that the culture reached a $40 \% \mathrm{pO}_{2}$ value at around $10 \mathrm{~h}$, and to keep this percentage constant during the experiment, the DCU automatically increased the stirring and airflow values (up to the maximum allowed level set by the operators) in the first $72 \mathrm{~h}$, thus meeting the microorganismmetabolic demand (Figure 3A, Figure S1). In the second experiment (Batch B), different profiles of stirring (300-600 rpm) and airflow $\left(102-120 \mathrm{~L} \cdot \mathrm{h}^{-1}\right)$ 
were set up in order to keep the $\mathrm{pO}_{2} \geq 30 \%$ (Table 1 , Figure 3B, Figure S1). These diverse conditions provided similar maximum values of biomass and apigenin concentration to Batch A but in shorter time, such that the maximum biomass was reached already at $24 \mathrm{~h}$ $\left(10.4 \pm 0.4 \mathrm{~g}_{\mathrm{cdw}} \cdot \mathrm{L}^{-1}\right)$, while the maximum apigenin production was obtained in only $48 \mathrm{~h}$ $\left(160.0 \pm 5.2 \mu \mathrm{g} \cdot \mathrm{L}^{-1}\right)$, and this increased the process productivity up to $3.3 \pm 0.1 \mu \mathrm{g} \cdot \mathrm{L}^{-1} \cdot \mathrm{h}^{-1}$ with an apigenin on biomass yield of $15.4 \pm 0.1 \mu \mathrm{g} \cdot \mathrm{g}_{\mathrm{cdw}}{ }^{-1}$ (Table 2, Figure 3B). The total carbon source consumption was about $35.2 \mathrm{~g} \cdot \mathrm{L}^{-1}$ in $120 \mathrm{~h}$, with an average consumption rate of $0.3 \mathrm{~g} \cdot \mathrm{L}^{-1} \cdot \mathrm{h}^{-1}$ and a yield of apigenin on the total carbon source of $4.6 \pm 0.1 \mu \mathrm{g} \cdot \mathrm{g}_{\text {totalc }}{ }^{-1}$ (Table 2, Figure 3B). The $\mathrm{pO}_{2}$ profile showed that the culture reached a $30 \%$ value at around $16 \mathrm{~h}$ and that the stirring and the airflow profiles seemed to perfectly satisfy the microorganism metabolic demand (Figure 3B, Figure S1). This second aeration/stirring and oxygenation condition was considered the best one for our purposes and used in the following batch experiments. A third type of experiment (Batch C) was also performed to investigate the influence of a higher amount of initial inoculum on the apigenin production, by keeping the same aeration/stirring conditions of Batch B (Table 1, Figure 3C). The culture showed a higher maximum biomass value of $11.1 \pm 0.2 \mathrm{gcdw}_{\mathrm{co}} \cdot \mathrm{L}^{-1}$ at $24 \mathrm{~h}$ and a prolonged phase of apigenin production up to $72 \mathrm{~h}$ with a maximum of $184.8 \pm 4.0 \mu \mathrm{g} \cdot \mathrm{L}^{-1}$, $15.0 \%$ higher than in Batch $B$, with a productivity of $2.6 \pm 0.1 \mu \mathrm{g} \cdot \mathrm{L}^{-1} \cdot \mathrm{h}^{-1}$ and an apigenin yield on biomass of $16.7 \pm 0.1 \mu \mathrm{g} \cdot \mathrm{g}_{\mathrm{cdw}}{ }^{-1}$ (Table 2, Figure 3C). The carbon source consumption was quicker and 1.65-fold higher than in Batch B, with a consumption of total carbon of about $58.2 \mathrm{~g} \cdot \mathrm{L}^{-1}$ in $120 \mathrm{~h}$, with an average consumption rate of $0.5 \mathrm{~g} \cdot \mathrm{L}^{-1} \cdot \mathrm{h}^{-1}$ and an yield of apigenin on the total carbon source of $3.2 \pm 0.1 \mu \mathrm{g} \cdot \mathrm{g}_{\text {totalc }}{ }^{-1}$ (Table 2, Figure 3C). As expected, as the nutrient ( $\mathrm{C}$ source) consumption was quicker, the $\mathrm{pO}_{2}$ profile also showed faster oxygen consumption, that reached a $30 \%$ value in only nine hours, thus almost half of the time that was needed in Batch B (Figure 3C, Figure S1). Furthermore, samples of biomass at different time points of batch experiments were observed through SEM analyses in order to eventually identify morphological variations of the mycelium in the diverse growth conditions (Figure 4).

Batch A

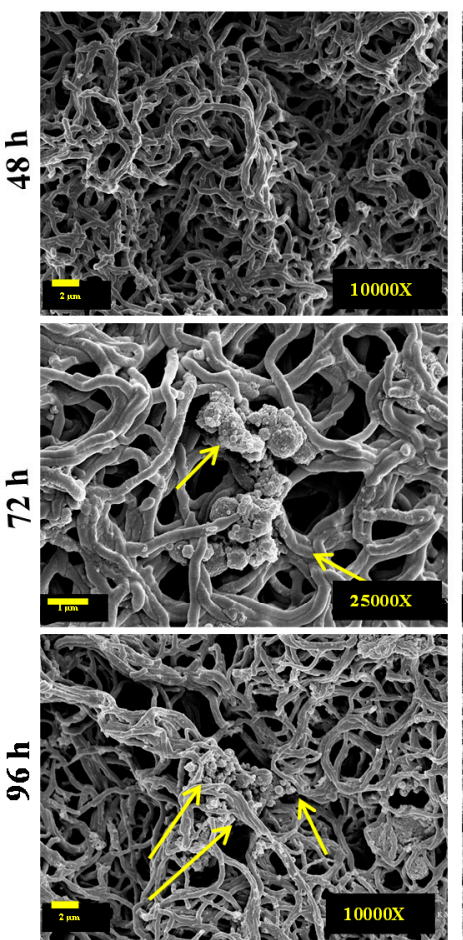

Batch B
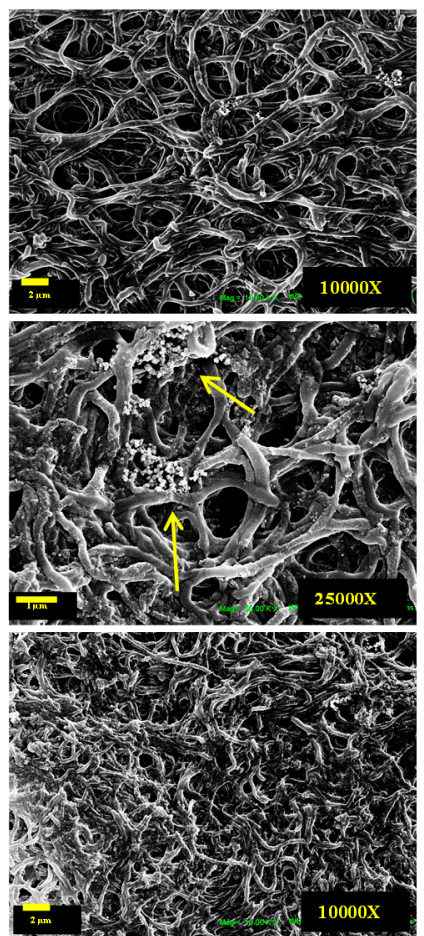

Batch C
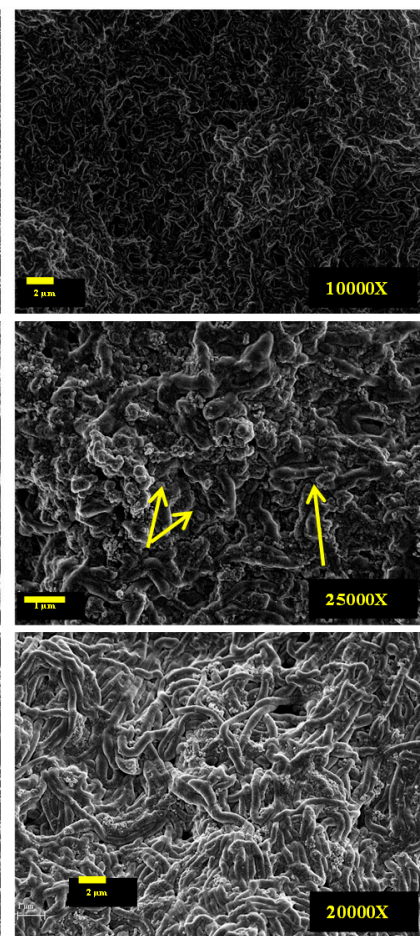

Batch D

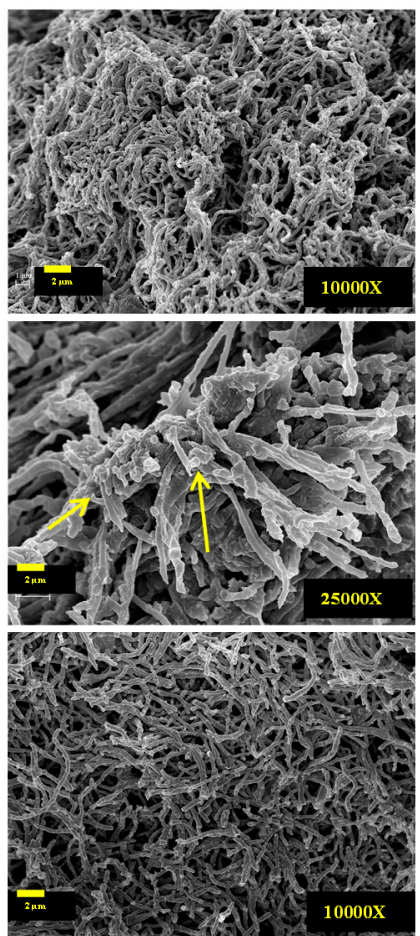

Figure 4. SEM analyses of Streptomyces albus-pAPI biomass samples of the different batch experiments at different time points. Deposits on the mycelium surfaces are indicated by the arrows. 
Morphological differences were clearly visible between the biomass samples of the three experiments after $48 \mathrm{~h}$ of growth: at this time point, the mycelium of Batch A was less developed and entangled than the mycelia of Batches B and C (Figure 4). The mycelium of Batch C, deriving from a higher volume of inoculum, seemed tighter than the other two in the SEM micrograph (Figure 4). This characteristic of the Batch C biomass was also visible at $72 \mathrm{~h}$ and afterwards, while a similarly tight entanglement was found in Batch B later in the experimental time, specifically at $96 \mathrm{~h}$. This recombinant strain also showed the typical dispersed mycelium morphology described for the $S$. albus wild type strain [30]. In all the batch samples, some deposits on the mycelium surfaces were clearly visible, starting from $72 \mathrm{~h}$ of growth, possibly due to the hydrophobic nature of the produced apigenin (Figure 4). Similar deposits were previously noted on $S$. roseochromogenes cells during the microbial bioconversion of another hydrophobic molecule such as hydrocortisone [47] (Figure 4).

\subsection{Apigenin Precursor Supplementation in Shake Flask and Batch Experiments}

Further experiments were performed in shake flasks and in bioreactor to investigate the possibility to improve apigenin production by supplementing the growth medium with appropriate precursors such as L-tyrosine and/or biotin. L-tyrosine is the first molecule involved in the apigenin biosynthetic pathway as a precursor of $p$-coumaroyl-CoA, while the biotin is a co-factor involved in the malonyl-CoA biosynthesis (Figure 1). $p$-coumaroylCoA and malonyl-CoA are then combined by the CHS enzyme in a 1 to 3 molar ratio to produce the chalcone molecule, which is then converted in apigenin through naringenin (Figure 1). In this paper, shake flask experiments were run for $120 \mathrm{~h}$ by adding L-tyrosine or biotin at three diverse concentrations (from 0.375 to $1.5 \mathrm{mM}$ ). The addition of the precursors did not significantly change the values of the final biomass, which were in the range from $5.6 \pm 0.2$ to $6.0 \pm 0.3 \mathrm{~g}_{\mathrm{cdw}} \cdot \mathrm{L}^{-1}$ in all of the experiments. The L-tyrosine supplementation allowed to enhance the apigenin concentration and the yields on biomass: in the case of its $0.375 \mathrm{mM}$ addition, the production and yield titers were 1.3- and 1.8-fold higher than those of the control $\left(197.0 \pm 11.6 \mu \mathrm{g} \cdot \mathrm{L}^{-1}\right.$ and $\left.53.0 \pm 0.1 \mu \mathrm{g} \cdot \mathrm{g}_{\mathrm{cdw}}{ }^{-1}\right)$; in the case of its $0.75 \mathrm{mM}$ supplementation, they were 2.1- and 1.8-fold higher than those of the control $\left(304.2 \pm 15.4 \mu \mathrm{g} \cdot \mathrm{L}^{-1}\right.$ and $\left.61.6 \pm 0.5 \mu \mathrm{g} \cdot \mathrm{g}_{\mathrm{cdw}}{ }^{-1}\right)$; while, finally, in the case of the addition of $1.5 \mathrm{mM}$ L-tyrosine, the values were 2.5- and 2.0-fold higher, respectively, than those of the control (364.4 $\pm 4.4 \mu \mathrm{g} \cdot \mathrm{L}^{-1}$ and $60.7 \pm 0.3 \mu \mathrm{g} \cdot \mathrm{g}_{\mathrm{cdw}}{ }^{-1}$ ) (Figure 5).

A further supplementation with $3.0 \mathrm{mM}$ of L-tyrosine did not result in any improvement (data not shown). The supplementations with biotin proved less effective, as in fact they did not enhance the production or the yield compared to the control, independently from the concentration used. A potential synergic effect of the two precursors in a 1 to 3 molar ratio was investigated by adding $0.5 \mathrm{mM}$ of L-tyrosine and $1.5 \mathrm{M}$ of biotin in the medium. This contemporary addition increased both the apigenin concentration and the $\mathrm{Y}_{\mathrm{apig} / \mathrm{X}}$ that resulted 1.8- and 2.0-fold higher compared to the control $\left(261.5 \pm 8.4 \mu \mathrm{g} \cdot \mathrm{L}^{-1}\right.$ and $\left.58.1 \pm 0.1 \mu \mathrm{g} \cdot \mathrm{g}_{\mathrm{cdw}}{ }^{-1}\right)$, respectively. Nevertheless, the enhancement was lower than the one obtained only with the L-tyrosine addition $(1.5 \mathrm{mM})$. Thus, taking into consideration all these data, obtained in shake flasks, batch experiments were run supplementing the medium with $1.5 \mathrm{mM}$ of L-tyrosine while keeping fixed the optimized stirring, aeration and inoculum strategies used in the Batch $C$ process (Table 1, Figure 6).

In these further experiments (Batch D), the biomass growth showed a maximum at $24 \mathrm{~h}$, as previously obtained, but the value was $11.0 \%$ lower than in Batch $C\left(10.0 \pm 0.1 \mathrm{~g}_{\mathrm{cdw}} \cdot \mathrm{L}^{-1}\right)$. The L-tyrosine was quickly up-taken: half of the amount was consumed in $24 \mathrm{~h}$, and it was completely used by the microorganism in only $48 \mathrm{~h}$ (Figure 6). The maximum apigenin concentration was almost double than the one reported in Batch $C\left(343.3 \pm 3.0 \mu \mathrm{g} \cdot \mathrm{L}^{-1}\right)$ and the production proved faster $(48 \mathrm{~h})$, thus enhancing the process productivity of 2.7fold $\left(7.1 \pm 0.1 \mu \mathrm{g} \cdot \mathrm{L}^{-1} \cdot \mathrm{h}^{-1}\right)$, while the $\mathrm{Y}_{\mathrm{apig} / \mathrm{X}}$ increased of 2.0 -fold $\left(34.3 \pm 0.1 \mu \mathrm{g} \cdot \mathrm{g}_{\mathrm{cdw}}{ }^{-1}\right)$ compared to previous experiments (Table 2, Figure 6). The $\mathrm{pO}_{2}(\%)$ profile and the total carbon source consumption were similar to those reported for Batch $C$ (about $58.1 \mathrm{~g} \cdot \mathrm{L}^{-1}$ of total carbon consumed in $120 \mathrm{~h}$ with an average consumption rate of $0.48 \mathrm{~g} \cdot \mathrm{L}^{-1} \cdot \mathrm{h}^{-1}$ ), but 
the $\mathrm{Y}_{\mathrm{apig} / \mathrm{S}}$ was 1.8-fold higher $\left(5.9 \pm 0.1 \mu \mathrm{g} \cdot \mathrm{g}_{\text {totalc }}{ }^{-1}\right.$ ) (Table 2, Figure 6). Morphological differences were noted, instead, by observing the biomass samples of this batch and comparing them to the Batch $\mathrm{C}$ samples (Figure 4). The mycelium was tight and developed as observed in the other experiment, but at $72 \mathrm{~h}$ and $96 \mathrm{~h}$, when the L-tyrosine was already completely up-taken, the hyphae were longer, thinner and they generally seemed to be better separated (Figure 4).

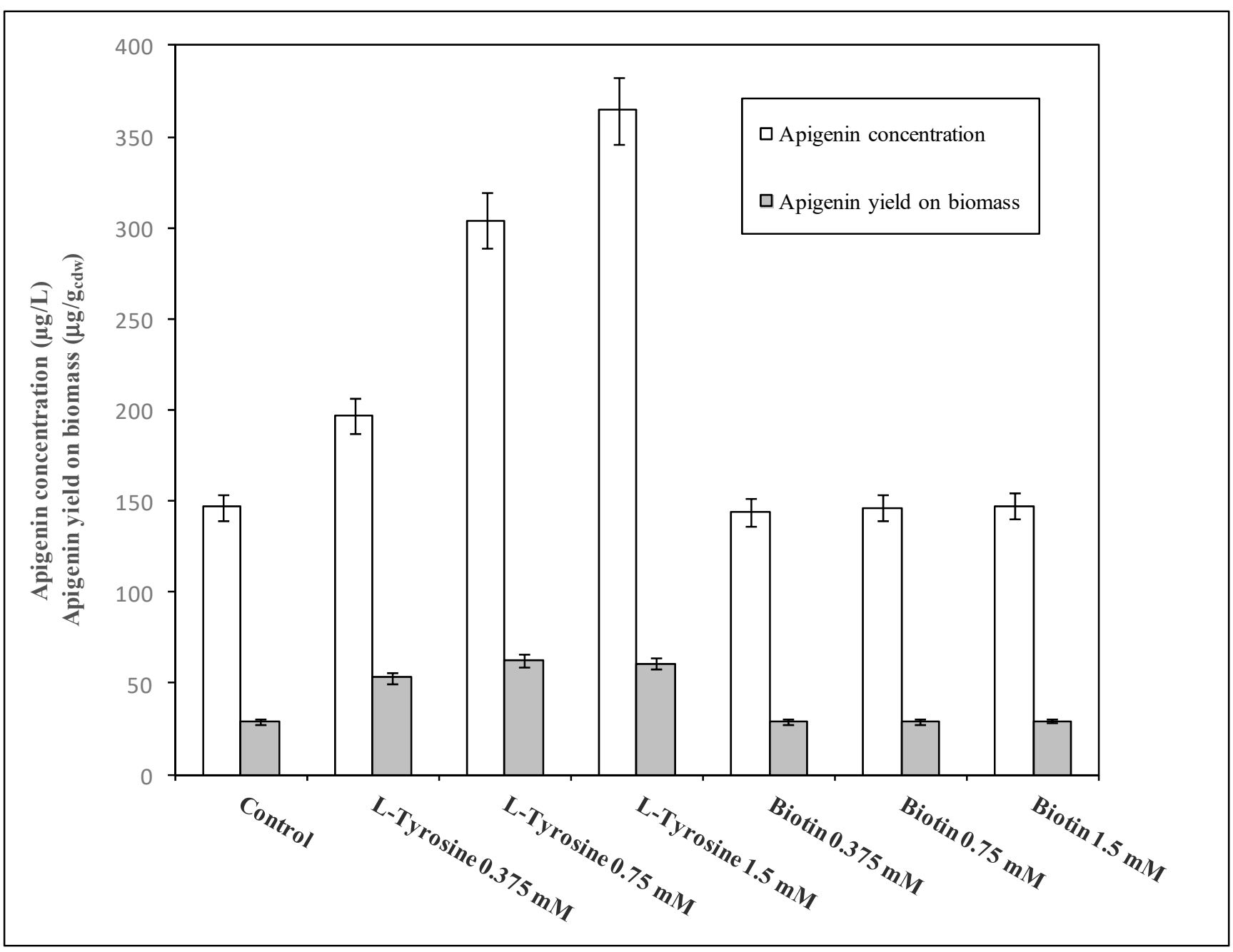

Figure 5. Shake flask experiments of Streptomyces albus-pAPI with supplementation of L-tyrosine and biotin as precursors, added at different concentrations: apigenin concentration and yield on biomass in comparison with the control. 


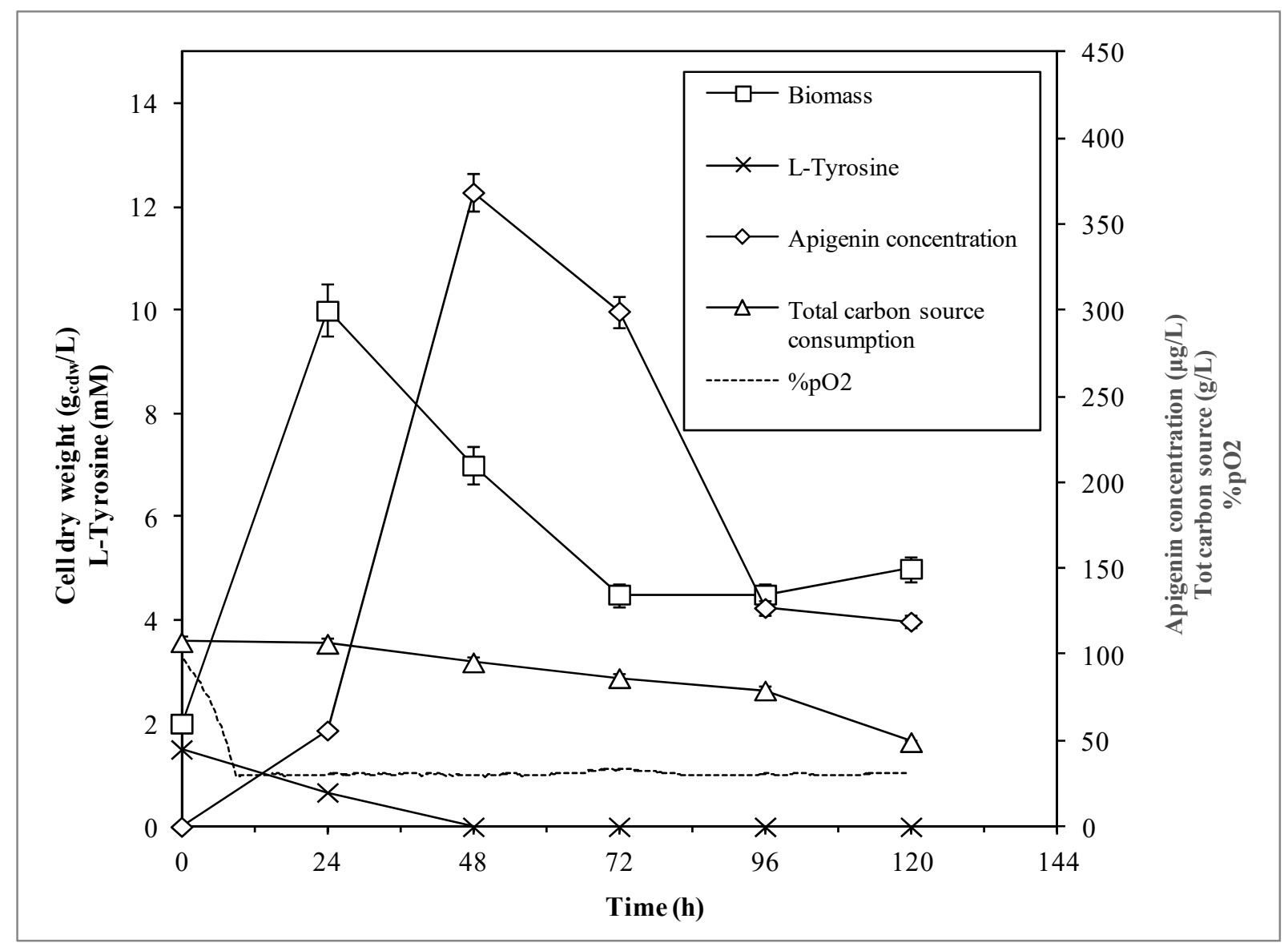

Figure 6. Batch experiments of Streptomyces albus-pAPI with the addition of $1.5 \mathrm{mM}$ L-tyrosine: kinetics of growth and apigenin concentration, total carbon source and L-tyrosine consumption and $\% \mathrm{pO}_{2}$ profile.

\section{Discussion}

Wild-type and recombinant streptomycetes are widely employed as platforms in the biotechnological production of drugs and other bioactive compounds, thanks to their enzymatic and metabolic versatility [38]. Streptomyces albus J1074 is particularly suitable for the effective introduction of heterologous DNA thanks to to the fact that it has a completely sequenced and easily modifiable genome that is the smallest one among the strains of the same genus; this small genome also enables its fast growth [48,49]. In addition, S. albus J1074 shows a typical disperse mycelium development that makes its cultures less dense and easier to be oxygenated than other Streptomyces strains [30]. For all these reasons, this strain is generally considered as a selected host for heterologous expression and very useful for industrial fermentation production processes of valuable metabolites such as antibiotics, natural compounds or anticancer agents [50]. In a previous paper, this strain was engineered for the production of apigenin, a flavone derived from plants with relevant bioactivity such as antioxidant, anti-carcinogenic and anti-inflammatory. However, the production titers, performed only in shake flasks starting from a spore inoculum, resulted low [30]. In this paper, for the first time, we tried to increase the apigenin biotechnological production by the recombinant $S$. albus-pAPI strain, also studying the pre-inoculum type. It is very well known that, due to the peculiar streptomycetes life cycle, the source, size, age and type of inoculum deeply influence the metabolism of the microorganism in the fermentation stage, and that it is a common practice to investigate inoculum conditions in process development studies to avoid unwanted and long lag phases, to reduce process time and to increase production yields [51]. For example, studies conducted on batch fermentations of Streptomyces clavuligerus demonstrated that both the inoculum age and type significantly impacted the production of clavulanic acid in 
industrial processes, particularly the productivity [52]. In many papers, authors preferred to use spores as inoculum, but in this case, a conditioning phase is required, that could last even several days, in order to induce germination $[30,51]$. In the streptomycetes life cycle, spores are more related to a quiescent phase which is used by the Streptomyces genus to survive to stressful environmental conditions, while the mycelial stage is actually more involved in the active synthesis of both primary and secondary metabolites $[38,53,54]$. Thus, using the mycelium as a starting seed for the fermentation process promotes the production of secondary metabolites better due to its higher metabolic activity $[51,55,56]$. In this research work, the first step was to compare the apigenin production starting from a mycelium or spore pre-inoculum in shake flasks. The results demonstrated that the cultures inoculated with the microorganism in the mycelial stage were quicker in producing apigenin, at a rate that was 1.8-fold higher than previously reported data [30]. Preparing liquid cultures starting from mycelium instead of spores probably allowed to skip the step of spore germination and to reach the main phase of apigenin production earlier, thus reducing the total process time. Furthermore, a sound design of a biotechnological fermentative production process based on the employment of streptomycetes needs a specific tuning of biophysical parameters and the study of the influence of gas transfer and shear stress on the hyphae growth [57]. Thus, agitation and aeration conditions in the vessel as well as the dissolved oxygen percentage are of great importance and key factors to wisely modulate in order to create the best culture conditions for the production of the molecules of interests $[39,58]$. In particular, agitation and aeration contribute to improve the homogeneity of the medium and provide the correct mass and oxygen transfer between the broth and the mycelium clumps. In fact, high dissolved oxygen percentages in the vessel during the fermentation are essential for the growth and also for the onset of primary or secondary metabolite production [39]. However, reaching a high oxygen transfer rate by increasing the agitation speed may result in mycelium shear stresses, causing damage to the hyphae integrity with consequent reduction in the metabolite yield $[59,60]$. Thus, a careful balance between these key factors in Streptomyces fermentation is needed in order to maximize the process performances [61]. In literature, according to our knowledge, there are no examples of the influence of these parameters on the heterologous production of flavones in bioreactors by using streptomycetes, while only a few examples of the growth of S. albus J1074 in lab-scale bioreactors are reported. This strain was used recently to produce the antibiotic lysolipin in a $4 \mathrm{~L}$ vessel by setting the agitation speed at $300 \mathrm{rpm}$ [62], or to produce fuels in a 2-L bioreactor process by using agitation values between 200 and $400 \mathrm{rpm}$ in order to maintain the $\mathrm{pO}_{2}$ percentage up to $40 \%$ [63]. In this work, instead, two different stirring and aeration profiles were investigated with the aim of keeping the $\mathrm{pO}_{2}$ at two different percentages, evaluating the effect of this parameter on the apigenin biosynthesis. Similar maximum biomass values and apigenin concentration were reached but with different kinetics: by using the profile with lower stirring and higher aeration fluxes, as in the Batch B experiments, a faster apigenin production and a better apigenin yield on the consumed carbon source were obtained. The two diverse profiles also induced a difference in the mycelium morphology that seemed tighter in the optimized conditions. As the heterologous production of this flavone can be related to the amount of bioactive biomass produced, higher biomass density may result in a higher titer and/or productivity. This hypothesis was confirmed in the batch process performed starting with a 2-fold inoculum. The data demonstrated that in this process, the carbon source consumption increased of $70 \%$ in $48 \mathrm{~h}$ and that it was not only used for the biomass formation, but also directed towards the apigenin synthesis that increased of $15.0 \%$ and lasted up to $72 \mathrm{~h}$. SEM pictures showed that the mycelium was highly developed already at $24 \mathrm{~h}$ and that a tight entanglement degree was maintained throughout the experiment. Despite the fact that the engineered S. albus-pAPI strain is able to produce apigenin synthesizing the necessary precursors by itself, the strategy of precursor addition in the growth medium might be useful to further improve the production but also to identify bottlenecks eventually occurring in the biosynthetic pathway. In a previous work, the supplementation of $S$. albus-pAPI medium 
with $1.5 \mathrm{mM}$ of $p$-coumaric acid and with $13.5 \mathrm{mM}$ of sodium malonate did not provide significant improvements in apigenin production [30]. In this work, we decided instead to explore both L-tyrosine and biotin supplementation strategies. L-tyrosine is the first precursor in the apigenin biosynthetic pathway; this could be a limiting factor as the pAPI plasmid does not include the gene involved in the synthesis of this amino acid and the basal L-tyrosine production in the cells may not be sufficient to support high rates of apigenin synthesis (Figure 1). Biotin, meanwhile, is a co-factor in the reaction that leads to the synthesis of malonyl-CoA, which in the apigenin pathway is necessary in the ratio of three molecules for each $p$-coumaroyl-CoA molecule (Figure 1). Since malonyl-CoA is also used by the cells in other pathways, for example as a precursor in fatty acid biosynthesis, its low availability could be a relevant bottleneck in the apigenin biosynthesis. Because, as already mentioned, the addition of sodium malonate did not increase the apigenin production, we explored in this paper the possibility of enhancing the malonyl-CoA availability, providing the co-factor used for its biosynthesis. The addition of $1.5 \mathrm{mM}$ L-tyrosine in the shake flask experiments allowed to obtain a 2.5 -fold increase in the apigenin concentration. On the contrary to what was expected, the addition of biotin, instead, did not. L-tyrosine supplementation was also used as a strategy in bioreactor experiments, coupled with the previously optimized fermentation conditions: in this way a 2.2-fold increased apigenin concentration was reached. Thus, compared to the data reported in the literature, this integrated optimization strategy led to enhance the apigenin concentration up to 4.3-fold, also shortening the process time of 10.7-fold. From an economic point of view, the strategy of supplementing $1.5 \mathrm{mM}$ of L-tyrosine to the medium is also sustainable. The addition would only cost about 0.17 euros per liter of culture medium, according to the actual price of the commercial L-tyrosine available on the market.

\section{Conclusions}

The optimization of the biotechnological production of apigenin by using a Streptomyces recombinant strain requires a multi-factorial analysis and an evidence-based experimental design. Here, an optimized procedure is suggested, starting from the study of the pre-inoculum conditions and the use of specific oxygenation profiles and innovative precursor addition approaches that enable to obtain increased production in a shorter process time. The relevant improvements reached in this research paved the way towards a further scale-up of the apigenin biotechnological production process.

Supplementary Materials: The following are available online at https:/ / www.mdpi.com/article/ 10.3390 / fermentation7030161/s1, Figure S1: The two different stirring and aeration profiles used in batch experiments of Streptomyces albus-pAPI.

Author Contributions: I.G.-d.-R., C.J.V. and F.L. constructed and provided the recombinant strain; O.F.R., S.B.F. and R.V. conducted the experiments; M.C. conducted SEM experiments; O.F.R. and S.B.F. conceived, drafted and wrote the manuscript; C.S. and F.L. reviewed the manuscript, C.S. obtained funds. All authors have read and agreed to the published version of the manuscript.

Funding: This work was financed by Campania Region-POR FESR 2007-2013 B25C13000290007 in the frame of project "Bio industrial processes-BIP" and by the grants "AGL2017-88095-R from MICINN, Spain" and "BP16023 to IGR from Programa Severo Ochoa Ayudas Predoctorales, Principality of Asturias". S.B.F. is enrolled in a Ph. D. program of the University of Campania "Luigi Vanvitelli with an industrial project called "Streptomycetes as technological platform for the improvement of biotechnological productive processes of pharmaceutical active principles and/or nutraceuticals of industrial interests". O.F.R. was supported by a research grant entitled "Development of new methods for the chemical-physical and biochemical characterization of biomolecules interesting as nutraceuticals and drugs" in the frame of the project PON01_01226 at the Department of Experimental Medicine of the University of Campania "Luigi Vanvitelli".

Data Availability Statement: The data that support the findings of this study are available on request from the corresponding author.

Conflicts of Interest: The authors have declared no conflicts of interest. 


\section{References}

1. Bhagwat, S.; Haytowitz, D.B.; Holden, J.M. USDA Database for the Flavonoid Content of Selected Foods; U.S. Department of Agriculture: Betsville, MD, USA, 2011.

2. Wang, M.; Firrman, J.; Liu, L.; Yam, K. A review on flavonoid apigenin: Dietary Intake, ADME, antimicrobial effects, and interactions with human gut microbiota. Biomed. Res. Int. 2019, 2019, 7010467. [CrossRef] [PubMed]

3. Manach, C.; Scalbert, A.; Morand, C.; Rémésy, C.; Jiménez, L. Polyphenols: Food sources and bioavailability. Am. J. Clin. Nutr. 2004, 79, 727-747. [CrossRef]

4. Gutiérrez-Del-Río, I.; Fernández, J.; Lombó, F. Plant Nutraceuticals as antimicrobial agents in food preservation: Terpenoids, polyphenols and thiols. Int. J. Antimicrob Agents 2018, 52, 309-315. [CrossRef] [PubMed]

5. Salehi, B.; Venditti, A.; Sharifi-Rad, M.; Kręgiel, D.; Sharifi-Rad, J.; Durazzo, A.; Lucarini, M.; Santini, A.; Souto, E.B.; Novellino, E.; et al. The therapeutic potential of apigenin. Int. J. Mol. Sci. 2019, 20, 1305. [CrossRef] [PubMed]

6. Imran, M.; Aslam Gondal, T.; Atif, M.; Shahbaz, M.; Batool Qaisarani, T.; Hanif Mughal, M.; Salehi, B.; Martorell, M.; Sharifi-Rad, J. Apigenin as an anticancer agent. Phytother. Res. 2020, 34, 1812-1828. [CrossRef]

7. Patel, D.; Shukla, S.; Gupta, S. Apigenin and cancer chemoprevention: Progress, potential and promise (Review). Int. J. Oncol. 2007, 30, 233-245. [CrossRef]

8. Liu, M.-M.; Ma, R.-H.; Ni, Z.-J.; Thakur, K.; Cespedes-Acuña, C.L.; Jiang, L.; Wei, Z.-J. Apigenin 7-O-glucoside promotes cell apoptosis through the PTEN/PI3K/AKT pathway and inhibits cell migration in cervical cancer HeLa cells. Food Chem. Toxicol. 2020, 146, 111843. [CrossRef]

9. Lee, Y.-J.; Park, K.-S.; Nam, H.-S.; Cho, M.-K.; Lee, S.-H. Apigenin causes necroptosis by inducing ROS accumulation, mitochondrial dysfunction, and ATP depletion in malignant mesothelioma cells. Korean J. Physiol. Pharmacol. 2020, $24,493-502$. [CrossRef]

10. Korga-Plewko, A.; Michalczyk, M.; Adamczuk, G.; Humeniuk, E.; Ostrowska-Lesko, M.; Jozefczyk, A.; Iwan, M.; Wojcik, M.; Dudka, J. Apigenin and hesperidin downregulate DNA repair genes in MCF-7 breast cancer cells and augment doxorubicin toxicity. Molecules 2020, 25, 4421. [CrossRef]

11. Li, Y.; Chen, X.; He, W.; Xia, S.; Jiang, X.; Li, X.; Bai, J.; Li, N.; Chen, L.; Yang, B. Apigenin enhanced antitumor effect of cisplatin in lung cancer via inhibition of cancer stem cells. Nutr. Cancer 2021, 73, 1489-1497. [CrossRef]

12. Woo, J.-S.; Choo, G.-S.; Yoo, E.-S.; Kim, S.-H.; Lee, J.-H.; Han, S.-H.; Kim, H.-J.; Jung, S.-H.; Park, Y.-S.; Kim, B.-S.; et al. Apigenin induces apoptosis by regulating Akt and MAPK pathways in human melanoma cell A375SM. Mol. Med. Rep. 2020, 22, 4877-4889. [CrossRef]

13. Gentile, D.; Fornai, M.; Colucci, R.; Pellegrini, C.; Tirotta, E.; Benvenuti, L.; Segnani, C.; Ippolito, C.; Duranti, E.; Virdis, A.; et al. The flavonoid compound apigenin prevents colonic inflammation and motor dysfunctions associated with high fat diet-induced obesity. PLoS ONE 2018, 13, e0195502. [CrossRef]

14. Ren, K.; Jiang, T.; Zhou, H.-F.; Liang, Y.; Zhao, G.-J. Apigenin retards atherogenesis by promoting ABCA1-mediated cholesterol efflux and suppressing inflammation. Cell. Physiol. Biochem. 2018, 47, 2170-2184. [CrossRef]

15. Sudhakaran, M.; Doseff, A.I. The targeted impact of flavones on obesity-induced inflammation and the potential synergistic role in cancer and the gut microbiota. Molecules 2020, 25, 2477. [CrossRef]

16. Tantowi, N.A.C.A.; Mohamed, S.; Lau, S.F.; Hussin, P. Comparison of diclofenac with apigenin-glycosides rich Clinacanthus Nutans extract for amending inflammation and catabolic protease regulations in osteoporotic-osteoarthritis Rat Model. DARU J. Pharm. Sci. 2020, 28, 443-453. [CrossRef]

17. Balez, R.; Steiner, N.; Engel, M.; Muñoz, S.S.; Lum, J.S.; Wu, Y.; Wang, D.; Vallotton, P.; Sachdev, P.; O’Connor, M.; et al. Neuroprotective effects of apigenin against inflammation, neuronal excitability and apoptosis in an induced pluripotent stem cell model of Alzheimer's disease. Sci. Rep. 2016, 6, 31450. [CrossRef] [PubMed]

18. Nabavi, S.F.; Khan, H.; D’onofrio, G.; Šamec, D.; Shirooie, S.; Dehpour, A.R.; Argüelles, S.; Habtemariam, S.; Sobarzo-Sanchez, E. Apigenin as neuroprotective agent: Of mice and men. Pharmacol. Res. 2018, 128, 359-365. [CrossRef] [PubMed]

19. Koo, H.; Schobel, B.; Scott-Anne, K.; Watson, G.; Bowen, W.H.; Cury, J.A.; Rosalen, P.L.; Park, Y.K. Apigenin and tt-farnesol with fluoride effects on S. mutans biofilms and dental caries. J. Dent. Res. 2005, 84, 1016-1020. [CrossRef]

20. Dong, J.; Qiu, J.; Wang, J.; Li, H.; Dai, X.; Zhang, Y.; Wang, X.; Tan, W.; Niu, X.; Deng, X.; et al. Apigenin alleviates the symptoms of Staphylococcus aureus pneumonia by inhibiting the production of alpha-hemolysin. FEMS Microbiol. Lett. 2013, 338, $124-131$. [CrossRef]

21. Kuo, C.-H.; Weng, B.-C.; Wu, C.-C.; Yang, S.-F.; Wu, D.-C.; Wang, Y.-C. Apigenin has anti-atrophic gastritis and anti-gastric cancer progression effects in Helicobacter pylori-infected mongolian gerbils. J. Ethnopharmacol. 2014, 151, 1031-1039. [CrossRef] [PubMed]

22. Su, Y.; Ma, L.; Wen, Y.; Wang, H.; Zhang, S. Studies of the in vitro antibacterial activities of several polyphenols against clinical isolates of methicillin-resistant Staphylococcus aureus. Molecules 2014, 19, 12630-12639. [CrossRef] [PubMed]

23. Özçelik, B.; Kartal, M.; Orhan, I. Cytotoxicity, antiviral and antimicrobial activities of alkaloids, flavonoids, and phenolic acids. Pharm. Biol. 2011, 49, 396-402. [CrossRef] [PubMed]

24. Chiang, L.-C.; Ng, L.-T.; Cheng, P.-W.; Chiang, W.; Lin, C.-C. Antiviral activities of extracts and selected pure constituents of Ocimumbasilicum. Clin. Exp. Pharmacol. Physiol. 2005, 32, 811-816. [CrossRef] [PubMed] 
25. Shibata, C.; Ohno, M.; Otsuka, M.; Kishikawa, T.; Goto, K.; Muroyama, R.; Kato, N.; Yoshikawa, T.; Takata, A.; Koike, K. The flavonoid apigenin inhibits hepatitis C virus replication by decreasing mature microRNA122 levels. Virology 2014, $462,42-48$. [CrossRef]

26. Rameshkumar, M.R.; Indu, P.; Arunagirinathan, N.; Venkatadri, B.; El-Serehy, H.A.; Ahmad, A. Computational selection of flavonoid compounds as inhibitors against SARS-CoV-2 main protease, RNA-dependent RNA polymerase and spike proteins: A molecular docking study. Saudi J. Biol. Sci. 2021, 28, 448-458. [CrossRef]

27. Trantas, E.A.; Koffas, M.A.G.; Xu, P.; Ververidis, F. When plants produce not enough or at all: Metabolic engineering of flavonoids in microbial hosts. Front. Plant Sci. 2015, 6. [CrossRef]

28. Owens, D.K.; Alerding, A.B.; Crosby, K.C.; Bandara, A.B.; Westwood, J.H.; Winkel, B.S.J. Functional analysis of a predicted flavonol synthase gene family in Arabidopsis. Plant Physiol. 2008, 147, 1046-1061. [CrossRef]

29. Falcone Ferreyra, M.L.; Rius, S.P.; Casati, P. Flavonoids: Biosynthesis, biological functions, and biotechnological applications. Front. Plant Sci. 2012, 3. [CrossRef]

30. Marín, L.; Gutiérrez-del-Río, I.; Yagüe, P.; Manteca, Á.; Villar, C.J.; Lombó, F. De novo biosynthesis of apigenin, luteolin, and eriodictyol in the actinomycete Streptomyces albus and production improvement by feeding and spore conditioning. Front. Microbiol. 2017, 8, 921. [CrossRef]

31. Leonard, E.; Yan, Y.; Lim, K.H.; Koffas, M.A.G. Investigation of two distinct flavone synthases for plant-specific flavone biosynthesis in Saccharomyces cerevisiae. Appl. Environ. Microbiol. 2005, 71, 8241-8248. [CrossRef] [PubMed]

32. Leonard, E.; Chemler, J.; Lim, K.H.; Koffas, M.A.G. Expression of a soluble flavone synthase allows the biosynthesis of phytoestrogen derivatives in Escherichia coli. Appl. Microbiol. Biotechnol. 2006, 70, 85-91. [CrossRef]

33. Park, S.R. Biosynthesis of plant-specific flavones and flavonols in Streptomyces venezuelae. J. Microbiol. Biotechnol. 2010, 20, 1295-1299. [CrossRef] [PubMed]

34. Miyahisa, I.; Funa, N.; Ohnishi, Y.; Martens, S.; Moriguchi, T.; Horinouchi, S. Combinatorial biosynthesis of flavones and flavonols in Escherichia coli. Appl. Microbiol. Biotechnol. 2006, 71, 53-58. [CrossRef] [PubMed]

35. Lee, H.; Kim, B.G.; Kim, M.; Ahn, J.-H. Biosynthesis of two flavones, apigenin and genkwanin, in Escherichia coli. J. Microbiol. Biotechnol. 2015, 25, 1442-1448. [CrossRef]

36. Thuan, N.H.; Chaudhary, A.K.; Van Cuong, D.; Cuong, N.X. Engineering co-culture system for production of apigetrin in Escherichia coli. J. Ind. Microbiol. Biotechnol. 2018, 45, 175-185. [CrossRef] [PubMed]

37. Cui, H.; Song, M.C.; Ban, Y.H.; Jun, S.Y.; Kwon, A.S.; Lee, J.Y.; Yoon, Y.J. High-yield production of multiple O-methylated phenylpropanoids by the engineered Escherichia coli-Streptomyces cocultivation system. Microb. Cell Fact. 2019, 18, 67. [CrossRef] [PubMed]

38. Barbuto Ferraiuolo, S.; Cammarota, M.; Schiraldi, C.; Restaino, O.F. Streptomycetes as platform for biotechnological production processes of drugs. Appl. Microbiol. Biotechnol. 2021, 105, 551-568. [CrossRef]

39. Olmos, E.; Mehmood, N.; Haj Husein, L.; Goergen, J.-L.; Fick, M.; Delaunay, S. Effects of Bioreactor Hydrodynamics on the Physiology of Streptomyces. Bioprocess Biosyst. Eng. 2013, 36, 259-272. [CrossRef]

40. Sanchez, J. New insights in Streptomyces fermentations. Ferment. Technol. 2012, 1. [CrossRef]

41. Fernandez, M.; Olek, A.; Walter, J.; Sanchez, J. Analysis of DNA methylation processes related to the inhibition of DNA synthesis by 5-azacytidine in Streptomyces antibioticus ETH 7451. Biol. Chem. 1998, 379, 559-562. [PubMed]

42. Restaino, O.F.; Marseglia, M.; De Castro, C.; Diana, P.; Forni, P.; Parrilli, M.; De Rosa, M.; Schiraldi, C. Biotechnological transformation of hydrocortisone to $16 \alpha$-hydroxy hydrocortisone by Streptomyces roseochromogenes. Appl. Microbiol. Biotechnol. 2014, 98, 1291-1299. [CrossRef]

43. Restaino, O.F.; Marseglia, M.; Diana, P.; Borzacchiello, M.G.; Finamore, R.; Vitiello, M.; D’Agostino, A.; De Rosa, M.; Schiraldi, C. Advances in the $16 \alpha$-hydroxy transformation of hydrocortisone by Streptomyces roseochromogenes. Process Biochem. 2016, 51, 1-8. [CrossRef]

44. Restaino, O.F.; di Lauro, I.; Cimini, D.; Carlino, E.; De Rosa, M.; Schiraldi, C. Monosaccharide precursors for boosting chondroitinlike capsular polysaccharide production. Appl. Microbiol. Biotechnol. 2013, 97, 1699-1709. [CrossRef]

45. Restaino, O.F.; di Lauro, I.; Di Nuzzo, R.; De Rosa, M.; Schiraldi, C. New insight into chondroitin and heparosan-like capsular polysaccharide synthesis by profiling of the nucleotide sugar precursors. Biosci. Rep. 2017, 37, BSR20160548. [CrossRef] [PubMed]

46. Mo, X.; Li, Y.; Tang, A.; Ren, Y. Simultaneous determination of phenylalanine and tyrosine in peripheral capillary blood by HPLC with ultraviolet detection. Clin. Biochem. 2013, 46, 1074-1078. [CrossRef] [PubMed]

47. Restaino, O.F.; Barbuto Ferraiuolo, S.; Perna, A.; Cammarota, M.; Borzacchiello, M.G.; Fiorentino, A.; Schiraldi, C. Biotechnological transformation of hydrocortisone into $16 \alpha$-hydroxyprednisolone by coupling Arthrobacter simplex and Streptomyces roseochromogenes. Molecules 2020, 25, 4912. [CrossRef]

48. Myronovskyi, M.; Tokovenko, B.; Brötz, E.; Rückert, C.; Kalinowski, J.; Luzhetskyy, A. Genome rearrangements of Streptomyces albus J1074 lead to the carotenoid gene cluster activation. Appl. Microbiol. Biotechnol. 2014, 98, 795-806. [CrossRef] [PubMed]

49. Zaburannyi, N.; Rabyk, M.; Ostash, B.; Fedorenko, V.; Luzhetskyy, A. Insights into naturally minimised Streptomyces albus J1074 Genome. BMC Genom. 2014, 15, 97. [CrossRef]

50. Baltz, R.H. Streptomyces and Saccharopolyspora hosts for heterologous expression of secondary metabolite gene clusters. J. Ind. Microbiol. Biotechnol. 2010, 37, 759-772. [CrossRef] [PubMed] 
51. Yepes-García, J.; Caicedo-Montoya, C.; Pinilla, L.; Toro, L.F.; Ríos-Estepa, R. Morphological differentiation of Streptomyces clavuligerus exposed to diverse environmental conditions and its relationship with clavulanic acid biosynthesis. Processes 2020, 8 , 1038. [CrossRef]

52. Pinto, L.S.; Vieira, L.M.; Pons, M.N.; Fonseca, M.M.R.; Menezes, J.C. Morphology and viability analysis of Streptomyces clavuligerus in industrial cultivation systems. Bioprocess Biosyst. Eng. 2004, 26, 177-184. [CrossRef]

53. Manteca, A.; Claessen, D.; Lopez-Iglesias, C.; Sanchez, J. Aerial hyphae in surface cultures of Streptomyces lividans and Streptomyces coelicolor originate from viable segments surviving an early programmed cell death event. FEMS Microbiol. Lett. 2007, 274, 118-125. [CrossRef] [PubMed]

54. Manteca, A.; Alvarez, R.; Salazar, N.; Yagüe, P.; Sanchez, J. Mycelium differentiation and antibiotic production in submerged cultures of Streptomyces coelicolor. Appl. Environ. Microbiol. 2008, 74, 3877-3886. [CrossRef] [PubMed]

55. Neves, A.A.; Vieira, L.M.; Menezes, J.C. Effects of preculture variability on clavulanic acid fermentation. Biotechnol. Bioeng. 2001, 72, 628-633. [CrossRef]

56. López-García, M.T.; Álvarez, J.R. Cell Immobilization of Streptomyces coelicolor: Effect on differentiation and actinorhodin production. Int. Microbiol. 2014, 75-80. [CrossRef]

57. Rosa, J.C.; Neto, A.B.; Hokka, C.O.; Badino, A.C. Influence of dissolved oxygen and shear conditions on clavulanic acid production by Streptomyces clavuligerus. Bioprocess Biosyst. Eng. 2005, 27, 99-104. [CrossRef]

58. Potumarthi, R.; Ch, S.; Jetty, A. Alkaline protease production by submerged fermentation in stirred tank reactor using Bacillus licheniformis NCIM-2042: Effect of aeration and agitation regimes. Biochem. Eng. J. 2007, 34, 185-192. [CrossRef]

59. Kim, S.W.; Hwang, H.J.; Xu, C.P.; Choi, J.W.; Yun, J.W. Effect of aeration and agitation on the production of mycelial biomass and exopolysaccharides in an enthomopathogenic fungus Paecilomycessinclairii. Lett Appl. Microbiol. 2003, 36, 321-326. [CrossRef]

60. Radchenkova, N.; Vassilev, S.; Martinov, M.; Kuncheva, M.; Panchev, I.; Vlaev, S.; Kambourova, M. Optimization of the aeration and agitation speed of Aeribacilluspalidus 418 exopolysaccharide production and the emulsifying properties of the product. Process Biochem. 2014, 49, 576-582. [CrossRef]

61. Zhou, Y.; Han, L.-R.; He, H.-W.; Sang, B.; Yu, D.-L.; Feng, J.-T.; Zhang, X. Effects of agitation, aeration and temperature on production of a novel glycoprotein GP-1 by Streptomyces kanasenisi ZX01 and scale-up based on volumetric oxygen transfer coefficient. Molecules 2018, 23, 125. [CrossRef]

62. Hofeditz, T.; Unsin, C.; Wiese, J.; Imhoff, J.; Wohlleben, W.; Grond, S.; Weber, T. Lysoquinone-TH1, a new polyphenolic tridecaketide produced by expressing the lysolipin minimal PKS II in Streptomyces albus. Antibiotics 2018, 7, 53. [CrossRef] [PubMed]

63. Yuzawa, S.; Mirsiaghi, M.; Jocic, R.; Fujii, T.; Masson, F.; Benites, V.T.; Baidoo, E.E.K.; Sundstrom, E.; Tanjore, D.; Pray, T.R.; et al. Short-chain ketone production by engineered polyketide synthases in Streptomyces albus. Nat. Commun. 2018, 9, 4569. [CrossRef] [PubMed] 